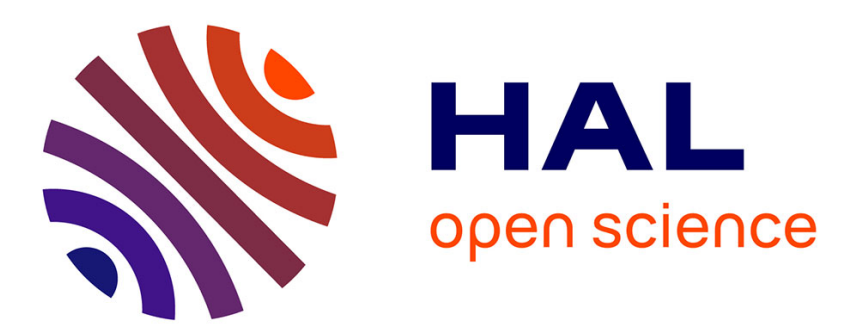

\title{
A new analytical model for predicting the thermal oxidation kinetics of composite organic matrices. Application to diamine cross-linked epoxy
} Xavier Colin, Fatima Essatbi, Justine Delozanne, Gurvan Moreau

\section{- To cite this version:}

Xavier Colin, Fatima Essatbi, Justine Delozanne, Gurvan Moreau. A new analytical model for predicting the thermal oxidation kinetics of composite organic matrices. Application

to diamine cross-linked epoxy. Polymer Degradation and Stability, 2021, 186, pp.1-13. 10.1016/j.polymdegradstab.2021.109513 . hal-03160505

\section{HAL Id: hal-03160505 https://hal.science/hal-03160505}

Submitted on 5 Mar 2021

HAL is a multi-disciplinary open access archive for the deposit and dissemination of scientific research documents, whether they are published or not. The documents may come from teaching and research institutions in France or abroad, or from public or private research centers.
L'archive ouverte pluridisciplinaire HAL, est destinée au dépôt et à la diffusion de documents scientifiques de niveau recherche, publiés ou non, émanant des établissements d'enseignement et de recherche français ou étrangers, des laboratoires publics ou privés. 


\title{
A new analytical model for predicting the thermal oxidation kinetics of composite organic $\mathrm{m}$ atrices. Application to diamine cross-linked epoxy
}

\author{
Xavier COLIN ${ }^{\mathrm{a}, *}$, Fatima ESSATBI ${ }^{\mathrm{a}}$, Justine DELOZANNE ${ }^{\mathrm{b}}$, Gurvan MOREAU ${ }^{\mathrm{b}}$ \\ a PIMM, Arts et Métiers Institute of Technology, CNRS, CNAM, HESAM University, 151 boulevard de l'Hôpital, 75013 Paris, France \\ ${ }^{\mathrm{b}}$ Safran Composites, A platform of Safran Tech, 33 avenue de la Gare, 91760 Ittevile, France
}

Keywords:

Diamine cross-linked epoxy

Thermal oxidation

Analytical kinetic model

Carbonyl build-up

Accelerated aging conditions

\begin{abstract}
A B S T R A C T
The system of differential equations derived from the so-called "closed-loop" mechanistic scheme was solved analytically by applying realistic proportionality assumptions between the different concentrations of reactive species during the entire course of the thermal oxidation. This new method of analytical resolution allowed obtaining a sounder kinetic model accurately describing the three first stages of the thermal oxidation kinetics: the induction period, the auto-acceleration of the oxidation kinetics at the end of the induction period, and the steady-state regime. This kinetic model was used to identify the thermal oxidation behavior at 120 and $150^{\circ} \mathrm{C}$ in a large range of oxygen partial pressures (typically between 0.21 and 10 bars) of two epoxy-diamine (EPO-DA) matrices. In addition, the kinetic model was used to determine the accelerated aging conditions representative of the cruising flight of a commercial airliner. It was found that the oxygen partial pressure must be increased much more than the temperature to avoid any deformation of the structural degradation state in the two EPO-DA matrices, thus leading to the definition of extreme environmental conditions very difficult to access in practice.
\end{abstract}

\section{Introduction}

The vast majority of composite material structures used in the civil aeronautical sector are made of epoxy or polyimide matrix reinforced with carbon fibers. Since the early 1980s, numerous studies [1-21] clearly showed that, during their in-service use just below their glass transition temperature, these composite materials can perish by matrix embrittlement induced by thermal oxidation. This latter is restricted to a superficial layer owing to its kinetic control by oxygen diffusion [22,23]. "Spontaneous" cracking can then occur in this superficial layer (without any external loading) due to the development of tensile stress gradients and the catastrophic fall of fracture properties [16,21,24], thus allowing oxygen penetration into deeper layers $[16,25,26]$. The repetition of this sequential scenario allows damage to propagate until the core of the composite material [16]. Thenceforth, failure can occur untimely.

The first attempts at kinetic modeling of the thermal oxidation process in composite materials were initiated in the early 1980s by Nelson [27], and continued for only a few years by Bowles and

\footnotetext{
* Corresponding author. Tel.: + 331442461 47, Fax: +33144246382. E-mail address: xavier.colin@ensam.eu (X. COLIN).
}

coll. $[28,29]$. For these authors, oxidation was a purely surface phenomenon leading to the formation of organic volatile compounds according to a one-step polymer/oxygen reaction, of which the apparent reaction order had to be determined experimentally, in particular from weight loss measurements. In the mid-1990s, Seferis and coll. $[6,7,30,31]$ perfected this first kinetic model by introducing differential equations derived from solid/gas reactions in order to describe the propagation of the oxidation front from the external surfaces towards the core of the composite material. Thus, for these authors, thermal ageing transformed the composite material into a sandwich structure consisting in a completely oxidized superficial layer surrounding a still intact core. The resulting weight losses were expressed as a function of the square root of time if the thermal oxidation kinetics was diffusion-controlled, otherwise they were written as a linear function of time. However, this approach was rapidly abandoned because it led to inconsistent results. As an example, it was several times reported that the weight loss measurements did not obey the two behavioral laws mentioned above. In addition, this approach did not give access to the oxidation profiles in the sample thickness. It was thus impossible to precisely locate, in the sample thickness, the critical oxidation events responsible for its embrittlement and subsequently, to fully apply the methodology currently used for lifetime prediction. 
Undoubtedly, the most realistic approach would have been to write a real coupling between oxygen diffusion and its chemical consumption (by the oxidation reaction), as already done since the 1950 s for unfilled hydrocarbon polymers [22, 23, 32-38]. In the case of unidirectional diffusion (e.g. in the sample thickness), this coupling can be written as follows:

$\frac{\partial \mathrm{C}}{\partial \mathrm{t}}=\mathrm{D} \frac{\partial^{2} \mathrm{C}}{\partial \mathrm{z}^{2}}-\mathrm{r}(\mathrm{C})$

where $C$ is the local oxygen concentration, $r(C)$ is the local rate of the oxygen chemical consumption (commonly called the "oxidation rate"), $\mathrm{D}$ is the coefficient of oxygen diffusion into the sample thickness, $\mathrm{t}$ is the exposure time and $\mathrm{z}$ is the spatial co-ordinate (i.e. the depth beneath the sample surface).

From this point of view, the kinetic model developed in the late 1990s by McManus and coll. [39-42] was much more satisfying. However, the oxidation rate was always expressed in a completely empirical form:

$r(C)=r_{0} \frac{\partial a(C)}{\partial t}$

$\frac{\partial \mathrm{a}}{\partial \mathrm{t}}=\mathrm{k}(1-\mathrm{a})^{\mathrm{n}} \mathrm{C}^{\mathrm{p}}$

where $r_{0}$ is a constant of proportionality, a is the local conversion ratio of the oxidation process generally expressed as a function of the local variation of the polymer density, $\mathrm{k}$ is a rate constant obeying an Arrhenius law, and $\mathrm{n}$ and $\mathrm{p}$ are apparent reaction orders.

Indeed, parameters $r_{0}, n$ and $p$ were very difficult to justify from mechanistic considerations. In fact, they were purely adjustable parameters. Their values were found to considerably vary with the thermal aging conditions, but the physical meaning of these variations was not well understood.

At the turn of the last century, our research group at Arts et Métiers proposed to benefit from the advances realized during the past half century by the scientific community on the oxidation of unfilled hydrocarbon polymers [22,23,32-38]. Thanks to a careful kinetic analysis of the so-called "closed-loop" mechanistic scheme [43], it was shown that a non-empirical analytical solution can be determined for the oxidation rate without making the usual simplifying assumptions [44] that seriously degraded the reliability of all the analytical kinetic models established until then. In particular, the following general expression was obtained only if considering the steady-state assumption for hydroperoxides and radical species $[45,46]$ :

$\mathrm{r}(\mathrm{C})=2 \mathrm{r}_{0} \frac{\beta \mathrm{C}}{1+\beta \mathrm{C}}\left[1-\frac{\beta \mathrm{C}}{2(1+\beta \mathrm{C})}\right]$

where $\mathrm{r}_{0}$ and $\beta$ are kinetic parameters which express as a function of the elementary rate constants and the substrate concentration. Both parameters are easily accessible from conventional laboratory techniques. Indeed, as schematized in Fig. $1, \beta^{-1}$ corresponds the critical value of the oxygen concentration $C_{C}$ above which oxygen excess is reached, and $r_{0}$ is the maximal value of the oxidation rate reached in oxygen excess.

The reliability of this analytical solution was successfully demonstrated in a wide range of temperatures and oxygen partial pressures for both epoxy and polyimide matrices [45,46]. Subsequently, Equation (4) was introduced into Equation (1) by several authors in order to determine the oxidation profiles, but also to predict the consequences of oxidation on mechanical properties, first of all in epoxy [45,47] and polyimide matrices [46,48,49], then in their corresponding composite materials [50-56].

It is important to remember here that, due to the starting (steady-state) assumption, Equation (4) is not valid at low conversion ratios of the oxidation reaction. Consequently, this equation

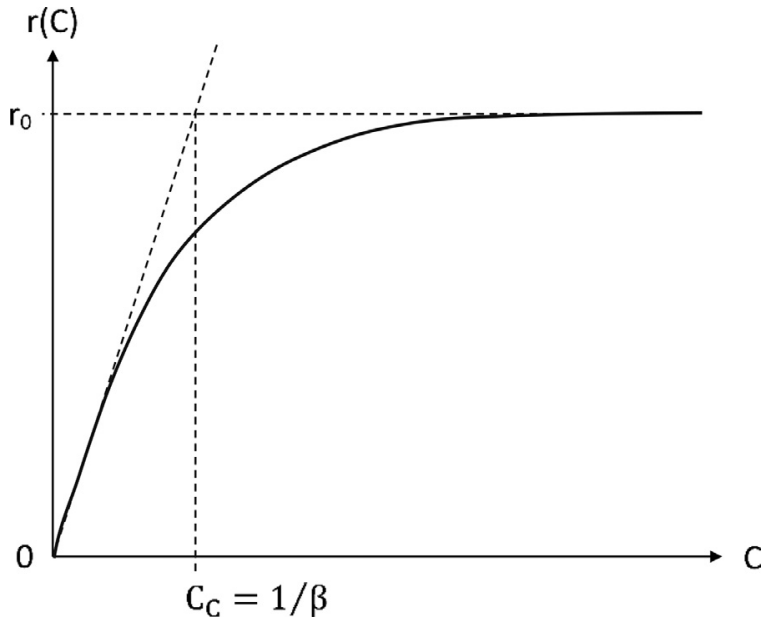

Fig. 1. Shape of the curve: oxidation rate versus oxygen concentration.

cannot be used for predicting the thermal oxidation kinetics during the induction period, but also the auto-acceleration of the oxidation kinetics at the end of the induction period. This is not very penalizing at high temperatures (typically for $\mathrm{T}>180^{\circ} \mathrm{C}$ ) at which accelerated aging tests in laboratory are usually performed, because the induction period is extremely short and therefore, these two first oxidation stages can be reasonably neglected. In contrast, the invalidity of Equation (4) prevents access to the effects of the very first oxidation events over relatively long time scales at lower temperatures (in particular, at the temperature of the industrial application), which then poses an serious problem for determining the lifetime of composite materials.

Aware of this weakness, the decision was taken to privilege the numerical approach (over the previous analytical approach) in order to eradicate all simplifying assumptions. Thus, the oxygen diffusion term (i.e. the Fick's second law) was directly introduced into the system of differential equations derived from the closed-loop mechanistic scheme, and this system was solved simultaneously in space $(\mathrm{z})$ and time $(\mathrm{t})$ using the numerical algorithms especially recommended for "stiff problems" of chemical kinetics [57]. It was found that the numerical solution gives very satisfying results for both epoxy and polyimide matrices, but also for their corresponding composite materials [58-60]. Subsequently, this new approach was generalized by several authors to other families of unfilled polymers and organic composite materials, e.g. in reference [61].

Despite this recognized success, the numerical approach poses several practical problems. In addition to being relatively complex to understand for non-specialists in chemistry and chemical kinetics, it is very cumbersome to deploy in the common mechanical calculation codes. Indeed, the calculation time increases almost exponentially with the number of freedom degrees and the dimension of the numerical problem to be solved, so that the computing possibilities are rapidly exceeded [62]. If there is no doubt that a numerical solution is essential for an advanced understanding of the thermal oxidation mechanisms and kinetics, it also appears clearly that a more rigorous analytical solution is lacking to allow mechanical researchers to take into account the durability of composite structures from the moment of their design and sizing. In addition, this analytical solution could be used to predict the development of damage in composite materials and their lifetime under service conditions.

The purpose of the present study is twice. At first, a new method for solving analytically the system of differential equations will be presented and the reliability of the corresponding analytical solution obtained for the oxidation rate will be checked nu- 
Table 1

Main oxidation sites in EPO-DA networks.

\begin{tabular}{ll}
\hline Starting epoxy monomer & Oxidation sites \\
DGEBA, DGEBF, DGEBD, TGPAP, TGTPM, TGMDA, etc... &
\end{tabular}

Abbreviations: Diglycidyl ether of bisphenol A (DGEBA), Diglycidyl ether of bisphenol F (DGEBF), Diglycidyl ether of bisphenol D (DGEBD), Triglycidyl ether of para-amino phenol (TGPAP), Triglycidyl ether of triphenyl methane (TGTPM), Tetraglycidyl ether of methylene dianiline (TGMDA).

merically. This new solution will be used to accurately identify the thermal oxidation behavior of two epoxy-diamine matrices (EPODA) considered for composite structure applications at low to moderate temperatures (typically between 70 and $150^{\circ} \mathrm{C}$ ) in the civil aeronautical sector, but also to position them within the whole EPO-DA family from a durability point of view. Then, the practical interest of having an analytical solution will be demonstrated through the determination of the accelerated aging conditions inducing a simple acceleration of the natural aging kinetics without any deformation of the structural degradation state. Indeed, the research of accelerated aging conditions perfectly representative of the natural aging remains a completely open challenge in industry even today. Knowing them would allow significantly reducing the duration and cost of experimental campaigns currently performed in industry in order to qualify a material for a given application.

\section{Theory}

\subsection{Closed-loop mechanistic scheme}

In EPO-DA matrices, the main oxidation sites are oxy-methylene (-O- $\left.\mathrm{CH}_{2}-\right)$, amino-methylene $\left(>\mathrm{N}-\mathrm{CH}_{2}-\right)$ and methanol groups $(>\mathrm{CH}-\mathrm{OH}$ ) because they contain the most labile $\mathrm{C}-\mathrm{H}$ bonds. Indeed, aliphatic $\mathrm{C}-\mathrm{H}$ bonds located in $\alpha$ of an heteroatom ( $\mathrm{O}$ or $\mathrm{N}$ ) are characterized by a much lower dissociation energy $\left(E_{D} \approx 376\right.$ $\mathrm{kJ} . \mathrm{mol}^{-1}$ ) than aliphatic $\mathrm{C}-\mathrm{H}$ bonds in polymethylenic sequences $\left(\mathrm{E}_{\mathrm{D}} \approx 393 \mathrm{~kJ} \cdot \mathrm{mol}^{-1}\right)$ and aromatic $\mathrm{C}-\mathrm{H}$ bonds $\left(\mathrm{E}_{\mathrm{D}} \approx 465 \mathrm{~kJ} \cdot \mathrm{mol}^{-1}\right)$ [63].

If oxy-methylene $\left(-\mathrm{O}-\mathrm{CH}_{2}-\right)$ and amino-methylene $\left(>\mathrm{N}-\mathrm{CH}_{2}-\right)$ groups can be already present in the starting epoxy monomers, in contrast, methanol groups $(>\mathrm{CH}-\mathrm{OH})$ are formed during the polymerization reaction between the epoxy monomer and diamine hardener. All these oxidation sites are reported in Table 1 , as well as the corresponding name of the starting epoxy monomer.

In this study, no difference will be made between these three types of oxidation sites. They will be all noted PH for a sake of simplicity.

In a recent publication [64], it was shown that the thermal oxidation of six EPO-DA matrices with very different glass transition temperatures can be accurately described using a single numerical kinetic model derived from the so-called closed-loop mechanistic scheme, provided that the impact of molecular mobility is taken into account in the Arrhenius laws of the different rate constants. This mechanistic scheme can be summarized by the following six reactions:

Initiation:

1) $\delta \mathrm{POOH} \rightarrow \lambda \mathrm{P}^{\bullet}+\mu \mathrm{PO}_{2}^{\bullet}\left(\mathrm{k}_{1}\right)$

Propagation:

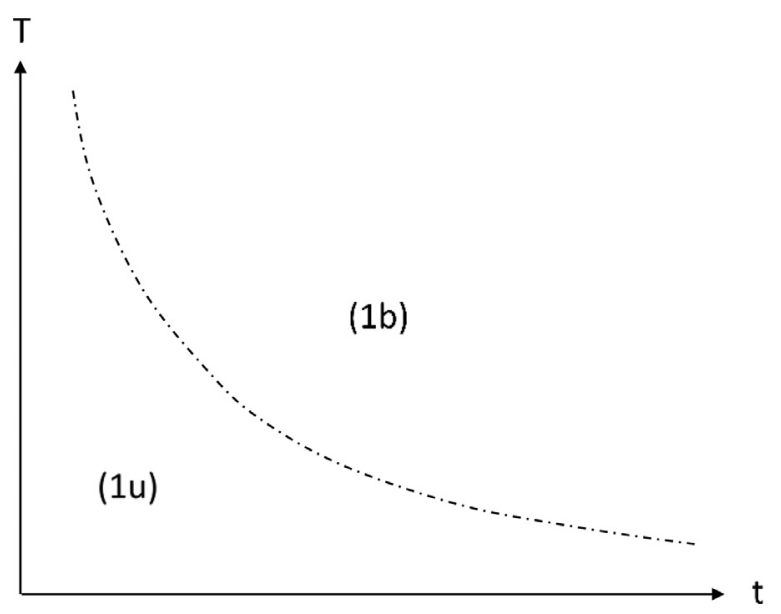

Fig. 2. Shape of the boundary delimitating thermal oxidation initiated by bimolecular (1b) and unimolecular $\mathrm{POOH}$ decompositions (1u).

2) $\mathrm{P}^{\bullet}+\mathrm{O}_{2} \rightarrow \mathrm{PO}_{2}^{\bullet}\left(\mathrm{k}_{2}\right)$

3) $\mathrm{PO}_{2}^{\bullet}+\mathrm{PH} \rightarrow \mathrm{POOH}+\mathrm{P}^{\bullet}\left(\mathrm{k}_{3}\right)$

Terminations:

4) $\mathrm{P}^{\bullet}+\mathrm{P}^{\bullet} \rightarrow$ Inactive products $\left(\mathrm{k}_{4}\right)$

5) $\mathrm{P}^{\bullet}+\mathrm{PO}_{2}^{\bullet} \rightarrow$ Inactive products $\left(\mathrm{k}_{5}\right)$

6) $\mathrm{PO}_{2} \bullet+\mathrm{PO}_{2}^{\bullet} \rightarrow$ Inactive products $+\mathrm{O}_{2}\left(\mathrm{k}_{6}\right)$

where $\mathrm{PH}, \mathrm{POOH}, \mathrm{P}^{\bullet}$ and $\mathrm{PO}_{2}{ }^{\bullet}$ designate an oxidation site, an hydroperoxide, alkyl and peroxy radicals, respectively. $\delta, \lambda$, and $\mu$ are stoichiometric coefficients and $\mathrm{k}_{\mathrm{i}}$ are reaction rate constants.

This general form of mechanistic scheme allows describing a large variety of thermal oxidative agings differing essentially in their initiation step. In most cases of thermal aging, $\mathrm{POOH}$ decomposition is exclusively unimolecular at high temperature (i.e. $\delta=1$, $\lambda=2, \mu=0$ and $\mathrm{k}_{1}=\mathrm{k}_{1 \mathrm{u}}$ ) or mainly bimolecular at low temperature $\left(\delta=2, \lambda=\mu=1\right.$, and $\mathrm{k}_{1}=\mathrm{k}_{1 \mathrm{~b}}$ ), but rarely a combination of both modes. The boundary delimiting the domains in which each initiation predominates over each other displays the shape of Fig. 2. This boundary corresponds to a critical hydroperoxide concentration $[\mathrm{POOH}]_{\mathrm{C}}$ reached when the respective rates of the two initiation modes are equal:

$\mathrm{k}_{1 \mathrm{u}}[\mathrm{POOH}]=\mathrm{k}_{1 \mathrm{~b}}[\mathrm{POOH}]^{2}$

i.e.

$[\mathrm{POOH}]_{\mathrm{C}}=\frac{\mathrm{k}_{1 \mathrm{u}}}{\mathrm{k}_{1 \mathrm{~b}}}$ 
Since both rate constants obey an Arrhenius' law, it comes:

$[\mathrm{POOH}]_{\mathrm{C}}=\mathrm{A}_{0} \operatorname{Exp}\left(-\frac{\mathrm{E}_{\mathrm{C}}}{\mathrm{RT}}\right)$

with $\mathrm{A}_{0}=\frac{\mathrm{k}_{1 \mathrm{u} 0}}{\mathrm{k}_{1 \mathrm{~b} 0}}$ and $\mathrm{E}_{\mathrm{C}}=\mathrm{E}_{1 \mathrm{u}}-\mathrm{E}_{1 \mathrm{~b}}$ where $\mathrm{k}_{1 \mathrm{u} 0}, \mathrm{E}_{1 \mathrm{u}}, \mathrm{k}_{1 \mathrm{~b} 0}$ and $\mathrm{E}_{1 \mathrm{~b}}$ are the Arrhenius' parameters of the rate constants $k_{1 u}$ and $k_{1 b}$, respectively.

For EPO-DA matrices, typical values for these Arrhenius' parameters are [64]: $\mathrm{k}_{1 \mathrm{u} 0}=1.3 \times 10^{13} \mathrm{~s}^{-1}, \mathrm{E}_{1 \mathrm{u}}=130 \mathrm{~kJ} \cdot \mathrm{mol}^{-1}$, $\mathrm{k}_{1 \mathrm{~b} 0}=1.9 \times 10^{9} \mathrm{~L} \cdot \mathrm{mol}^{-1} \cdot \mathrm{s}^{-1}$ and $\mathrm{E}_{1 \mathrm{~b}}=90 \mathrm{~kJ} \cdot \mathrm{mol}^{-1}$.

Since $E_{1 u}>E_{1 b}$, then $E_{C}>0$ and $[\mathrm{POOH}]_{C}$ is an increasing function of temperature. As an example, the numerical application of Equation (7) for EPO-DA matrices gives: $[\mathrm{POOH}]_{\mathrm{C}}=1.7 \times 10^{-2}$ mol. $\mathrm{L}^{-1}$ at $100^{\circ} \mathrm{C}, 7.9 \times 10^{-2} \mathrm{~mol} . \mathrm{L}^{-1}$ at $150^{\circ} \mathrm{C}$, and $2.6 \times 10^{-1}$ mol. $\mathrm{L}^{-1}$ at $200^{\circ} \mathrm{C}$.

Different chemical (e.g. FTIR spectroscopy and iodometry) or calorimetric techniques (DSC) can be used to measure the initial hydroperoxide concentration $[\mathrm{POOH}]_{0}$. For weakly pre-oxidized polymers, $[\mathrm{POOH}]_{0}$ is often close to $10^{-2}$ mol.l ${ }^{-1}[65,66]$. This value is of the same order of magnitude as $[\mathrm{POOH}]_{\mathrm{C}}$ at the two exposure temperatures under investigation (i.e. 120 and $150^{\circ} \mathrm{C}$ ). That is the reason why, in the present article, it will be considered that thermal oxidation is directly initiated in bimolecular mode:

1b) $2 \mathrm{POOH} \rightarrow \mathrm{P}^{\bullet}+\mathrm{PO}_{2}^{\bullet}\left(\mathrm{k}_{1 \mathrm{~b}}\right)$

\subsection{System of differential equations}

At the low conversion ratios of the thermal oxidation reaction (i.e. for $[\mathrm{PH}] \approx[\mathrm{PH}]_{0} \approx$ constant), the following system of differential equations can be derived from the closed-loop mechanistic scheme:

$$
\begin{aligned}
\frac{\mathrm{d}\left[\mathrm{P}^{\bullet}\right]}{\mathrm{dt}}= & \mathrm{k}_{1 \mathrm{~b}}[\mathrm{POOH}]^{2}-\mathrm{k}_{2} \mathrm{C}\left[\mathrm{P}^{\bullet}\right]+\mathrm{k}_{3}\left[\mathrm{PO}_{2}^{\bullet}\right][\mathrm{PH}]-2 \mathrm{k}_{4}\left[\mathrm{P}^{\bullet}\right]^{2} \\
& -\mathrm{k}_{5}\left[\mathrm{P}^{\bullet}\right]\left[\mathrm{PO}_{2}^{\bullet}\right]
\end{aligned}
$$

$$
\begin{aligned}
\frac{\mathrm{d}\left[\mathrm{PO}_{2}^{\bullet}\right]}{\mathrm{dt}}= & \mathrm{k}_{1 \mathrm{~b}}[\mathrm{POOH}]^{2}+\mathrm{k}_{2} \mathrm{C}\left[\mathrm{P}^{\bullet}\right]-\mathrm{k}_{3}\left[\mathrm{PO}_{2}^{\bullet}\right][\mathrm{PH}]-\mathrm{k}_{5}\left[\mathrm{P}^{\bullet}\right]\left[\mathrm{PO}_{2}^{\bullet}\right] \\
& -2 \mathrm{k}_{6}\left[\mathrm{PO}_{2}^{\bullet}\right]^{2}
\end{aligned}
$$

$$
\frac{\mathrm{d}[\mathrm{POOH}]}{\mathrm{dt}}=-2 \mathrm{k}_{1 \mathrm{~b}}[\mathrm{POOH}]^{2}+\mathrm{k}_{3}\left[\mathrm{PO}_{2} \cdot\right][\mathrm{PH}]
$$

where the oxygen concentration $C$ is related to the oxygen partial pressure $\mathrm{P}_{\mathrm{O} 2}$ in the exposure environment by the classical Henry's law:

$$
\mathrm{C}=\mathrm{S} \cdot \mathrm{P}_{\mathrm{O} 2}(11)
$$

and $\mathrm{S}$ is the coefficient of oxygen solubility into the polymer matrix.

There is no rigorous analytical solution for this system of differential equations, which can be solved numerically without any simplifying assumption. However, an approached analytical solution would be very useful because it would allow appreciating the behavioral trends of the reactive species $\left[\mathrm{P}^{\bullet}\right],\left[\mathrm{PO}_{2}{ }^{\bullet}\right],[\mathrm{POOH}]$ with key exposure parameters, in particular: temperature $\mathrm{T}$ and oxygen partial pressure $\mathrm{P}_{\mathrm{O} 2}$. In addition, this analytical solution would then allow calculating key physico-chemical properties, from a practical point of view, because they can be checked experimentally, such as: oxygen consumption $\mathrm{Q}$ carbonyl build-up $[\mathrm{P}=\mathrm{O}]$, weight changes $\Delta \mathrm{m} / \mathrm{m}_{0}$, etc. (see section 2.5).

Analytical solving is only possible through the use of simplifying assumptions. The most common assumption is the so-called "steady state" assumption according to which the radical concentrations remain constant throughout the exposure duration. This assumption can only be justified in the steady-state regime where the decomposition of hydroperoxides equilibrates their formation. According to Equation (10), it can be thus written:

$2 \mathrm{k}_{1 \mathrm{~b}}[\mathrm{POOH}]_{\infty}^{2}=\mathrm{k}_{3}\left[\mathrm{PO}_{2}^{\bullet}\right]_{\infty}[\mathrm{PH}]$

where $[\mathrm{POOH}]_{\infty}$ and $\left[\mathrm{PO}_{2}{ }^{\bullet}\right]_{\infty}$ are the steady concentrations of hydroperoxides and peroxy radicals, respectively.

In summary, the application of the steady-state assumption to hydroperoxides is equivalent to considering a constant initiation rate for the thermal oxidation. Therefore, the concentrations of the two radical species should rapidly tend towards their steady values: $\left[\mathrm{P}^{\bullet}\right]_{\infty}$ and $\left[\mathrm{PO}_{2}{ }^{\bullet}\right]_{\infty}$.

However, it is inconceivable to consider that the radical concentrations are constant during the induction period because this would mean that the radical species have absolutely no influence on the thermal oxidation kinetics. In oxygen excess, Tobolsky et al. [32] used an artefact to round this difficulty. They assumed that the sum of the radical concentrations (i.e. $\left[\mathrm{P}^{\bullet}\right]+\left[\mathrm{PO}_{2}{ }^{\bullet}\right]$ ) is also a constant whereas each individual radical concentration can vary freely, which leads finally to:

$\frac{\mathrm{d}[\mathrm{P} \bullet}{\mathrm{dt}}+\frac{\mathrm{d}\left[\mathrm{PO}_{2}^{\bullet}\right]}{\mathrm{dt}}=0$

i.e.

$2 \mathrm{k}_{1 \mathrm{~b}}[\mathrm{POOH}]^{2}=2 \mathrm{k}_{6}\left[\mathrm{PO}_{2} \cdot\right]^{2}$

i.e.

$\left[\mathrm{PO}_{2}^{\bullet}\right]=\left(\frac{\mathrm{k}_{1 \mathrm{~b}}}{\mathrm{k}_{6}}\right)^{1 / 2}[\mathrm{POOH}]$

These results are physically reasonable insofar as only hydroperoxides and peroxy radicals are considered. Indeed, it was shown that the corresponding concentrations of these two reactive species increase in a pseudo-exponential manner with exposure time $[67,68]$, which is in perfect agreement with the available experimental data. In contrast, the concentration changes in alkyl radicals are completely unrealistic because, according to Equation (13), $\left[\mathrm{P}^{\bullet}\right]$ would be maximum at the beginning of exposure and would decrease continuously to finally vanish when reaching the steadystate regime, while the thermal oxidation reaction would be in its auto-acceleration phase:

$\left[\mathrm{P}^{\bullet}\right]=\left[\mathrm{PO}_{2}^{\bullet}\right]_{\infty}-\left[\mathrm{PO}_{2}^{\bullet}\right]$

It seemed to us that a sound analytical kinetic model, aimed at describing accurately the thermal oxidation kinetics during the induction period and the auto-acceleration of the oxidation kinetics at the end of the induction period, and at predicting the induction time and the lifetime of EPO-DA matrices, cannot be based on the steady-state assumption. In other words, this latter must be replaced by a more physically reasonable and mathematically consistent assumption. How to choose such an assumption?

\subsection{First novelty for solving the system of differential equations}

In the previous section, it was shown that the Equation (15) obtained in oxygen excess can be used as a starting assumption. Indeed, the idea that, during the entire course of thermal oxidation, $\left[\mathrm{PO}_{2}{ }^{\bullet}\right]$ is proportional to $[\mathrm{POOH}]$ is quite realistic whatever the oxygen concentration [68]. Consequently, it was decided to generalize this assumption to the entire range of oxygen concentrations:

$\left[\mathrm{PO}_{2}^{\bullet}\right]=\mathrm{m}[\mathrm{POOH}]$

where $m$ is a function of the oxygen concentration $C$.

The mathematical expression of $\mathrm{m}$ can be established by applying the steady-state assumption to radical species. In the general case, Equation (13) leads to:

$2 \mathrm{k}_{1 \mathrm{~b}}[\mathrm{POOH}]^{2}=2 \mathrm{k}_{4}\left[\mathrm{P}^{\bullet}\right]^{2}+2 \mathrm{k}_{5}\left[\mathrm{P}^{\bullet}\right]\left[\mathrm{PO}_{2}^{\bullet}\right]+2 \mathrm{k}_{6}\left[\mathrm{PO}_{2}^{\bullet}\right]^{2}$ 
The introduction of Equation (12) into Equation (18) leads to:

$\mathrm{k}_{4}\left[\mathrm{P}^{\bullet}\right]^{2}+\mathrm{k}_{5}\left[\mathrm{P}^{\bullet}\right]\left[\mathrm{PO}_{2}^{\bullet}\right]-\frac{\mathrm{k}_{3}[\mathrm{PH}]}{2}\left[\mathrm{PO}_{2}^{\bullet}\right]+\mathrm{k}_{6}\left[\mathrm{PO}_{2}^{\bullet}\right]^{2}=0$

whose the positive root is:

$\left[\mathrm{P}^{\bullet}\right]=\frac{\mathrm{k}_{5}\left[\mathrm{PO}_{2}^{\bullet}\right]}{2 \mathrm{k}_{4}}\left\{-1+\left[1+\psi\left(\frac{\left[\mathrm{PO}_{2}^{\bullet}\right]_{0}}{\left[\mathrm{PO}_{2}^{\bullet}\right]}-1\right)\right]^{1 / 2}\right\}$

where $\Psi$ is a kinetic parameter quantifying the competition between the different terminations of radical species:

$\psi=\frac{4 \mathrm{k}_{4} \mathrm{k}_{6}}{\mathrm{k}_{5}^{2}}$

and $\left[\mathrm{PO}_{2}{ }^{\bullet}\right]_{0}$ is the steady concentration of peroxy radicals in oxygen excess $[67,68]$ :

$\left[\mathrm{PO}_{2}^{\bullet}\right]_{0}=\frac{\mathrm{k}_{3}[\mathrm{PH}]}{2 \mathrm{k}_{6}}$

If, as shown by Gillen et al. [69], $\psi<<1$, then there is a more or less wide range of oxygen concentrations for which:

$1 \geq \frac{\left[\mathrm{PO}_{2}^{\bullet}\right]}{\left[\mathrm{PO}_{2}^{\bullet}\right]_{0}}>\frac{5 \psi}{1+5 \psi}$

In this range of oxygen concentrations, Equation (20) can be simplified as follows:

$\left[\mathrm{P}^{\bullet}\right]=\frac{\mathrm{k}_{6}}{\mathrm{k}_{5}}\left(\left[\mathrm{PO}_{2}^{\bullet}\right]_{0}-\left[\mathrm{PO}_{2}^{\bullet}\right]\right)$

If introducing Equation (24) into Equation (9) and if applying the steady-state assumption to peroxy radicals, it comes finally:

$\left[\mathrm{PO}_{2}\right]_{\infty}=\frac{\mathrm{k}_{3}[\mathrm{PH}]}{2 \mathrm{k}_{6}} \frac{\beta \mathrm{C}}{1+\beta \mathrm{C}}$

where $\beta^{-1}$ corresponds to the critical value of the oxygen concentration $C_{C}$ above which oxygen excess is reached:

$\beta=\frac{1}{\mathrm{C}_{\mathrm{C}}}=\frac{\mathrm{k}_{6} \mathrm{k}_{2}}{\mathrm{k}_{5} \mathrm{k}_{3}[\mathrm{PH}]}$

The corresponding critical value of the oxygen partial pressure $\mathrm{P}_{\mathrm{O} 2 \mathrm{C}}$ in the exposure environment is deduced from the classical Henry's law (Eq. 11):

$\mathrm{P}_{\mathrm{O} 2 \mathrm{C}}=\frac{\mathrm{C}_{\mathrm{C}}}{\mathrm{S}}=\frac{1}{\beta \mathrm{S}}=\frac{\mathrm{k}_{5} \mathrm{k}_{3}[\mathrm{PH}]}{\mathrm{k}_{6} \mathrm{k}_{2} \mathrm{~S}}$

Finally, Equation (12) leads to:

$[\mathrm{POOH}]_{\infty}=\left(\frac{\mathrm{k}_{3}[\mathrm{PH}]}{2 \mathrm{k}_{1 \mathrm{~b}}}\left[\mathrm{PO}_{2}\right]_{\infty}\right)^{1 / 2}=\frac{\mathrm{k}_{3}[\mathrm{PH}]}{2\left(\mathrm{k}_{1 \mathrm{~b}} \mathrm{k}_{6}\right)^{1 / 2}}\left(\frac{\beta \mathrm{C}}{1+\beta \mathrm{C}}\right)^{1 / 2}$

and

$\mathrm{m}=\frac{\left[\mathrm{PO}_{2}^{\bullet}\right]}{[\mathrm{POOH}]}=\frac{\left[\mathrm{PO}_{2}^{\bullet}\right]_{\infty}}{[\mathrm{POOH}]_{\infty}}=\left(\frac{\mathrm{k}_{1 \mathrm{~b}}}{\mathrm{k}_{6}}\right)^{1 / 2}\left(\frac{\beta \mathrm{C}}{1+\beta \mathrm{C}}\right)^{1 / 2}$

It is now possible to integrate Equation (10). The introduction of Equation (29) into Equation (10) leads to:

$\frac{\mathrm{d}[\mathrm{POOH}]}{\mathrm{dt}}=-2 \mathrm{k}_{1 \mathrm{~b}}[\mathrm{POOH}]^{2}+\mathrm{K}[\mathrm{POOH}]$

where $\mathrm{K}$ is a rate constant expressed by:

$\mathrm{K}=\mathrm{mk}_{3}[\mathrm{PH}]=\mathrm{k}_{3}[\mathrm{PH}]\left(\frac{\mathrm{k}_{1 \mathrm{~b}}}{\mathrm{k}_{6}}\right)^{1 / 2}\left(\frac{\beta \mathrm{C}}{1+\beta \mathrm{C}}\right)^{1 / 2}$

Equation (30) can be rewritten such as:

$\frac{\mathrm{d}[\mathrm{POOH}]}{\mathrm{dt}}=-\mathrm{K}\left(\frac{[\mathrm{POOH}]^{2}}{[\mathrm{POOH}]_{\infty}}-[\mathrm{POOH}]\right)$ i.e.

$\frac{\frac{\mathrm{d}[\mathrm{POOH}]}{[\mathrm{POOH}]_{\infty}}}{\frac{[\mathrm{POOH}]^{2}}{[\mathrm{POOH}]_{\infty}^{2}}-\frac{[\mathrm{POOH}]}{[\mathrm{POOH}]_{\infty}}}=-\mathrm{K} \mathrm{dt}$

i.e.

$\left(\frac{1}{\frac{[\mathrm{POOH}]}{[\mathrm{POOH}]_{\infty}}-1}-\frac{1}{\frac{[\mathrm{POOH}]}{[\mathrm{POOH}]_{\infty}}}\right) \frac{\mathrm{d}[\mathrm{POOH}]}{[\mathrm{POOH}]_{\infty}}=-\mathrm{K} \mathrm{dt}$

The integration of Equation (34) with respect to time t leads to:

$\operatorname{Ln}\left(1-\frac{[\mathrm{POOH}]_{\infty}}{[\mathrm{POOH}]}\right)=-\mathrm{Kt}+\mathrm{a}$

where $\mathrm{a}$ is a constant to be determined by considering the initial conditions, i.e. $[\mathrm{POOH}]=[\mathrm{POOH}]_{0}$ when $\mathrm{t}=0$.

Rearranging Equation (35) in a more adequate form leads finally to:

$\frac{[\mathrm{POOH}]_{\infty}}{[\mathrm{POOH}]}=1+\mathrm{b} \operatorname{Exp}(-\mathrm{K} \mathrm{t})$

i.e.

$[\mathrm{POOH}]=\frac{[\mathrm{POOH}]_{\infty}}{1+\mathrm{b} \operatorname{Exp}(-\mathrm{K} \mathrm{t})}$

with

$\mathrm{b}=\frac{[\mathrm{POOH}]_{\infty}-[\mathrm{POOH}]_{0}}{[\mathrm{POOH}]_{0}}$

For weakly pre-oxidized samples, $[\mathrm{POOH}]_{\infty} \gg[\mathrm{POOH}]_{0}$. Experimental measurements $[65,66]$ show that: $[\mathrm{POOH}]_{\infty}>10[\mathrm{POOH}]_{0}$, therefore it can be reasonably considered that: $\mathrm{b}>>1$. In a first approach, a value of $b=10$ was chosen in this study.

Then, the introduction of Equation (37) into Equation (29) gives:

$\left[\mathrm{PO}_{2}^{\bullet}\right]=\frac{\left[\mathrm{PO}_{2}^{\bullet}\right]_{\infty}}{1+\mathrm{b} \operatorname{Exp}(-\mathrm{Kt})}$

Similarly, the introduction of Equation (37) into Equation (24) gives:

$\left[\mathrm{P}^{\bullet}\right]=\frac{\mathrm{k}_{3}[\mathrm{PH}]}{2 \mathrm{k}_{5}}\left(1-\frac{\beta \mathrm{C}}{1+\beta \mathrm{C}} \frac{1}{1+\mathrm{b} \operatorname{Exp}(-\mathrm{Kt})}\right)$

Undoubtedly, the proportionality assumption between $\left[\mathrm{PO}_{2}{ }^{\bullet}\right]$ and $[\mathrm{POOH}]$ leads to sounder analytical solutions for $\left[\mathrm{PO}_{2}{ }^{\circ}\right]$ and $[\mathrm{POOH}]$ which are valid in almost the entire range of oxygen concentrations, except at the very low oxygen concentrations not satisfying Equation (23). This validity range can be rewritten such as:

$\beta C>5 \psi$

In contrast, this analytical method used for solving the system of differential equations is not completely satisfying because Equation (40), obtained by applying the steady-state assumption to radical species (Eq. 24), gives always unrealistic changes of [ $\left.\mathrm{P}^{\bullet}\right]$ with exposure time. As in Equation (16), [ $\left.\mathrm{P}^{\bullet}\right]$ decreases with exposure time, but fortunately here, this concentration remains very low and does not vanish when reaching the steady-state regime:

$\left[\mathrm{P}^{\bullet}\right]_{\infty}=\frac{\mathrm{k}_{3}[\mathrm{PH}]}{2 \mathrm{k}_{5}} \frac{1}{1+\beta \mathrm{C}}$

Despite this undeniable improvement, it was decided to look for a more realistic equation. 
Table 2

Result of the analytical solving of the system of differential equations without using the classical simplifying assumptions. Initial and steady values.

\begin{tabular}{lllll}
\hline Species & Analytical solution & Initial value & Steady value General case & Steady value Oxygen excess \\
\hline$[\mathrm{POOH}]$ & $\frac{[\mathrm{POOH}]_{\infty}}{1+\mathrm{b} E x p(-\mathrm{Kt})}$ & {$[\mathrm{POOH}]_{0}$} & $\frac{\mathrm{k}_{3}[\mathrm{PH}]}{2\left(\mathrm{k}_{1} \mathrm{k}_{6}\right)^{1 / 2}}\left(\frac{\beta \mathrm{C}}{1+\beta \mathrm{C}}\right)^{1 / 2}$ & $\frac{\mathrm{k}_{3}[\mathrm{PH}]}{2\left(\mathrm{k}_{16} \mathrm{k}_{6}\right)^{1 / 2}}$ \\
{$\left[\mathrm{PO}_{2} \cdot\right]$} & $\frac{\left[\mathrm{PO}{ }_{2} \cdot\right]_{\infty}}{1+\mathrm{E} \operatorname{Exp}(-\mathrm{K} \mathrm{t})}$ & $\left.\left[\mathrm{PO}_{2}\right]_{\infty}\right]_{\infty}[\mathrm{POOH}]_{0}$ & $\frac{\mathrm{k}_{3}[\mathrm{PH}]}{2 \mathrm{POOH})_{\infty}} \frac{\beta \mathrm{C}}{1+\beta \mathrm{C}}$ & $\frac{\mathrm{k}_{3}[\mathrm{PH}]}{2 \mathrm{k}_{6}}$ \\
{$[\mathrm{P}]$} & {$\left[\mathrm{P}^{\bullet}\right]_{\infty}\left(\frac{1}{1+\mathrm{b} \operatorname{Exp}(-\mathrm{K} \mathrm{t})}\right)^{2}$} & {$\left[\mathrm{P}^{\bullet}\right]_{\infty} \frac{[\mathrm{POOH}]_{0}^{2}}{[\mathrm{POOH}]_{\infty}^{2}}$} & $\frac{\mathrm{k}_{3}[\mathrm{PH}]}{2 \mathrm{k}_{5}} \frac{1}{1+\beta \mathrm{C}}$ & $\frac{\mathrm{k}_{3}[\mathrm{PH}]}{2 \mathrm{k}_{5}} \frac{1}{\beta \mathrm{C}}$ \\
\hline
\end{tabular}

\subsection{Second novelty for solving the system of differential equations}

As in the previous section, it seemed to us interesting to start from the observation that, during the entire course of thermal oxidation, $\left[\mathrm{P}^{\bullet}\right]$ is proportional to $[\mathrm{POOH}]^{2}$ [68]. From the Equations (28) and (42) established in the steady-state regime, it can be written:

$\mathrm{m}^{\prime}=\frac{\left[\mathrm{P}^{\bullet}\right]_{\infty}}{[\mathrm{POOH}]_{\infty}^{2}}=\frac{2 \mathrm{k}_{1 \mathrm{~b}}}{\mathrm{k}_{2} \mathrm{C}}$

It was decided to generalize this assumption to the entire course of thermal oxidation:

$\left[\mathrm{P}^{\bullet}\right]=\mathrm{m}[\mathrm{POOH}]^{2}=\left[\mathrm{P}^{\bullet}\right]_{\infty}\left(\frac{1}{1+\mathrm{b} \operatorname{Exp}(-\mathrm{Kt})}\right)^{2}$

Undoubtedly, the proportionality assumption between $\left[\mathrm{P}^{\bullet}\right]$ and $[\mathrm{POOH}]$ allows avoiding the last contradictions induced by the application of the steady-state assumption to radical species. Indeed, in Equation (44), $\left[\mathrm{P}^{\bullet}\right]$ increases with exposure time up to its maximal value in the steady-state regime. It should be recalled here that this sounder analytical solution for $\left[\mathrm{P}^{\bullet}\right]$ is also valid in almost the entire range of oxygen concentrations, except at very low oxygen concentrations (see Eq. 41).

All these new analytical solutions, obtained for [POOH], $\left[\mathrm{PO}_{2}{ }^{\bullet}\right]$ and $\left[\mathrm{P}^{\bullet}\right]$, have been compiled in Table 2 , as well as their initial and steady values (both in the general case and in oxygen excess).

\subsection{Calculation of the physico-chemical properties}

From these analytical solutions, it is now possible to calculate several key physico-chemical properties, from a practical point of view, because these properties can be checked experimentally. Undoubtedly, hydroperoxide concentration $[\mathrm{POOH}]$ and oxygen consumption $Q$ are the most relevant properties because their mathematical expressions can be derived from the closed-loop mechanistic scheme without using any additional adjustable parameter. Thus, they can be used to accurately determine the different rate constants from experiments.

Recall that the rate of oxygen consumption writes:

$\mathrm{r}(\mathrm{C})=-\frac{\mathrm{d}\left[\mathrm{O}_{2}\right]}{\mathrm{dt}}=\mathrm{k}_{2} \mathrm{C}\left[\mathrm{P}^{\bullet}\right]-\mathrm{k}_{6}\left[\mathrm{PO}_{2}^{\bullet}\right]^{2}$

i.e.

$\mathrm{r}(\mathrm{C})=2 \mathrm{k}_{1 \mathrm{~b}}[\mathrm{POOH}]^{2}-\mathrm{k}_{6}\left[\mathrm{PO}_{2}^{\bullet}\right]^{2}$

If replacing $[\mathrm{POOH}]$ and $\left[\mathrm{PO}_{2}{ }^{\bullet}\right]$ by their analytical solutions in Equation (46), it comes:

$\mathrm{r}(\mathrm{C})=\frac{\mathrm{k}_{3}^{2}[\mathrm{PH}]^{2}}{2 \mathrm{k}_{6}} \frac{\beta \mathrm{C}}{1+\beta \mathrm{C}}\left(1-\frac{\beta \mathrm{C}}{2(1+\beta \mathrm{C})}\right)\left(\frac{1}{1+\mathrm{b} \operatorname{Exp}(-\mathrm{K} \mathrm{t})}\right)^{2}$

i.e.

$r(C)=r_{\infty}\left(\frac{1}{1+b \operatorname{Exp}(-K t)}\right)^{2}$ with

$\mathrm{r}_{\infty}=2 \mathrm{r}_{0} \frac{\beta \mathrm{C}}{1+\beta \mathrm{C}}\left(1-\frac{\beta \mathrm{C}}{2(1+\beta \mathrm{C})}\right)$

and

$\mathrm{r}_{0}=\frac{\mathrm{k}_{3}^{2}[\mathrm{PH}]^{2}}{4 \mathrm{k}_{6}}$

where $r_{\infty}$ and $r_{0}$ are the respective steady rates of oxygen consumption in the general case and in oxygen excess.

It should be noted that the rate constant $\mathrm{K}$ (Eq. 31) can be also expressed such as:

$\mathrm{K}=2\left(\mathrm{r}_{0} \mathrm{k}_{1 \mathrm{~b}}\right)^{1 / 2}\left(\frac{\beta \mathrm{C}}{1+\beta \mathrm{C}}\right)^{1 / 2}$

The integration of Equation (48) with respect to time t gives access to the concentration of oxygen consumed by the chemical reaction $Q$ :

$\mathrm{Q}=\int_{0}^{\mathrm{t}} \mathrm{r}(\mathrm{C}) \mathrm{dt}$

i.e.

$\mathrm{Q}=\mathrm{r}_{\infty} \int_{0}^{\mathrm{t}} \frac{\mathrm{dt}}{[1+\mathrm{b} \operatorname{Exp}(-\mathrm{Kt})]^{2}}$

i.e.

$\mathrm{Q}=\mathrm{r}_{\infty}\left[\int_{0}^{\mathrm{t}} \mathrm{dt}-\int_{0}^{\mathrm{t}} \frac{\mathrm{b} \operatorname{Exp}(-\mathrm{Kt}) \mathrm{dt}}{1+\mathrm{b} \operatorname{Exp}(-\mathrm{K} t)}-\int_{0}^{\mathrm{t}} \frac{\mathrm{b} \operatorname{Exp}(-\mathrm{K} \mathrm{t}) \mathrm{dt}}{(1+\mathrm{b} \operatorname{Exp}(-\mathrm{K} \mathrm{t}))^{2}}\right]$

i.e.

$\mathrm{Q}=\frac{\mathrm{r}_{\infty}}{\mathrm{K}}\left[\mathrm{Kt}+\mathrm{Ln}\left(\frac{1+\mathrm{b} \operatorname{Exp}(-\mathrm{K} t)}{1+\mathrm{b}}\right)-\frac{1}{1+\mathrm{b} \operatorname{Exp}(-\mathrm{K} \mathrm{t})}+\frac{1}{1+\mathrm{b}}\right]$

This curve admits as asymptotic straight-line $Q_{\infty}$ in the steadystate regime (i.e. when $\mathrm{t} \rightarrow \infty$ ):

$\mathrm{Q}_{\infty}=\frac{\mathrm{r}_{\infty}}{\mathrm{K}}\left[\mathrm{Kt}-\operatorname{Ln}(1+\mathrm{b})-\frac{\mathrm{b}}{1+\mathrm{b}}\right]$

It is now possible to deduce the mathematical expression of the induction time corresponding to the intersection point of this straight-line with the time axis:

$\mathrm{t}_{\mathrm{i}}=\frac{1}{\mathrm{~K}}\left[\operatorname{Ln}(1+\mathrm{b})+\frac{\mathrm{b}}{1+\mathrm{b}}\right]$

As $\mathrm{b}>>1$, a correct approximation is:

$\mathrm{t}_{\mathrm{i}} \approx \frac{1-\operatorname{Ln}\left(\mathrm{Y}_{0}\right)}{\mathrm{K}}$

with

$\mathrm{Y}_{0}=\frac{[\mathrm{POOH}]_{0}}{[\mathrm{POOH}]_{\infty}}$

It should be recalled here that $\mathrm{K}$ in a hyperbolic function of oxygen concentration Eq. 51). Thus, Equations (47) and ((58) allows 
highlighting a very important feature of the thermal oxidation kinetics, already put in evidence on many unfilled polymers in the literature, e.g. in PP [70]: Oxidation kinetics does not only depends on temperature, but also on the oxygen partial pressure in the exposure environment. Indeed, increasing the oxygen concentration C within the sample not only reduces the induction time (Eq. 58), but also increases the oxidation rate (Eq. 47). Consequently, oxygen partial pressure can be used in combination with temperature to accelerate the thermal oxidation kinetics.

Another key property, largely used in the literature to estimate the orders of magnitude of the different rate constants, is the carbonyl concentration $[\mathrm{P}=\mathrm{O}]$. In the closed-loop mechanism, these oxidation products can only be formed in initiation (1) and termination reactions (6) through specific chemical events (e.g. $\beta$ scission, disproportionation, etc.) generally in competition with many other chemical events, in particular with hydrogen abstraction which gives alcohols. Consequently, the calculation of the formation rate of these oxidation products requires the use of adjustable parameters:

$\frac{\mathrm{d}[\mathrm{P}=\mathrm{O}]}{\mathrm{dt}}=\gamma_{1 \mathrm{CO}} \mathrm{k}_{1 \mathrm{~b}}[\mathrm{POOH}]^{2}+\gamma_{6 \mathrm{CO}} \mathrm{k}_{6}\left[\mathrm{PO}_{2}\right]^{2}$

where $\gamma_{1 \text { co }}$ and $\gamma_{6 \mathrm{CO}}$ are the respective formation yields of carbonyl products in initiation (1) and termination (6).

In a recent publication [64], it has been shown that at 120 and $150^{\circ} \mathrm{C}$ for the two EPO-DA matrices under study, $\gamma_{1 \mathrm{CO}}=\gamma_{6 \mathrm{CO}}=$ $0.30 \pm 0.05$. This average value will be kept in this study.

If replacing $[\mathrm{POOH}]$ and $\left[\mathrm{PO}_{2}{ }^{\bullet}\right]$ by their analytical solutions in Equation (60), it comes:

$$
\begin{aligned}
\frac{\mathrm{d}[\mathrm{P}=\mathrm{O}]}{\mathrm{dt}}= & \frac{\mathrm{k}_{3}^{2}[\mathrm{PH}]^{2}}{4 \mathrm{k}_{6}} \frac{\beta \mathrm{C}}{1+\beta \mathrm{C}}\left(\gamma_{1 \mathrm{CO}}+\gamma_{6 \mathrm{CO}} \frac{\beta \mathrm{C}}{1+\beta \mathrm{C}}\right) \\
& \times\left(\frac{1}{1+\mathrm{b} \operatorname{Exp}(-\mathrm{K} \mathrm{t})}\right)^{2}
\end{aligned}
$$

i.e.

$\frac{\mathrm{d}[\mathrm{P}=\mathrm{O}]}{\mathrm{dt}}=\mathrm{r}_{\mathrm{CO} \infty}\left(\frac{1}{1+\mathrm{b} \operatorname{Exp}(-\mathrm{Kt})}\right)^{2}$

with

$\mathrm{r}_{\mathrm{CO} \infty}=\mathrm{r}_{0} \frac{\beta \mathrm{C}}{1+\beta \mathrm{C}}\left(\gamma_{1 \mathrm{CO}}+\gamma_{6 \mathrm{CO}} \frac{\beta \mathrm{C}}{1+\beta \mathrm{C}}\right)$

The integration of Equation (62) with respect to time $t$ gives a mathematical expression similar in form to $\mathrm{Q}$ thus admitting the same induction time $t_{\mathrm{i}}$ :

$$
\begin{aligned}
{[\mathrm{P}=0]=} & \frac{\mathrm{r}_{\mathrm{CO} \infty}}{\mathrm{K}}\left[\mathrm{Kt}+\operatorname{Ln}\left(\frac{1+\mathrm{b} \operatorname{Exp}(-\mathrm{Kt})}{1+\mathrm{b}}\right)\right. \\
& \left.-\frac{1}{1+\mathrm{b} \operatorname{Exp}(-\mathrm{K} t)}+\frac{1}{1+\mathrm{b}}\right]
\end{aligned}
$$

\section{Experimental}

\subsection{Materials}

The two EPO-DA matrices under study result from the reaction of a common bi-functional epoxy monomer: diglycidyl ether of bisphenol $F$ (DGEBF) or diglycidyl ether of bisphenol $A$ (DGEBA), with an aromatic diamine hardener: 9,9-bis(3-chloro-4aminophenyl)fluorene (CAF). Films of unfilled matrices, with thicknesses typically ranging between 25 and $100 \mu \mathrm{m}$, were produced by compression molding then post-cured under primary vacuum (i.e. $10^{-3}$ bar) in accordance with the recommended industrial cure cycle, with the objective of reaching the maximum crosslinking
Table 3

Molar mass of the repetitive monomer unit (mUCR), density (r) and concentration in oxidation sites (PH) for perfect EPO-DA networks.

\begin{tabular}{lllll}
\hline Matrix & $\mathrm{m}_{\mathrm{UCR}}\left(\mathrm{g} \cdot \mathrm{mol}^{-1}\right)$ & $\rho$ & {$[\mathrm{PH}]\left(\mathrm{mol} . \mathrm{L}^{-1}\right)$} & $\mathrm{T}_{\mathrm{g}}\left({ }^{\circ} \mathrm{C}\right)$ \\
\hline DGEBF-CAF & 1041 & 1.25 & 14.4 & 158 \\
DGEBA-CAF & 1097 & 1.25 & 13.7 & 182 \\
\hline
\end{tabular}

Abbreviations: Diglycidyl ether of bisphenol F (DGEBF), Diglycidyl ether of bisphenol A (DGEBA) and 9,9-bis(3-chloro-4-aminophenyl)fluorene (CAF).

density while avoiding any undesired pre-oxidation before exposure to thermal ageing. These precautions allowed minimizing the concentration in structural defects (in particular, in hydroperoxides $\mathrm{POOH}$ ) in both EPO-DA matrices. That is the reason why, as explained in previous in section 2.3 (see Equation (38)), a high value was chosen for parameter $b$ in this study (typically $b=10$ ).

After processing, the films were characterized by conventional laboratory techniques. In particular, their glass transition temperature $\left(T_{g}\right)$ was determined by differential scanning calorimetry (DSC, with a $20^{\circ} \mathrm{C} \cdot \mathrm{min}^{-1}$ heating rate, under nitrogen) and confirmed by mechanical spectrometry (DMA, in tensile mode, with a $1 \mathrm{~Hz}$ frequency and a $2^{\circ} \mathrm{C} \cdot \mathrm{min}^{-1}$ heating rate, under nitrogen). These measurements were found very close to the theoretical values of $\mathrm{T}_{\mathrm{g}}$ determined with the Di Marzo's equation for perfect networks (i.e. without dangling chains) [71]: $\mathrm{T}_{\mathrm{g}} \approx 158^{\circ} \mathrm{C}$ for DGEBF-CAF and $182^{\circ} \mathrm{C}$ for DGEBA-CAF.

In addition, the concentration in oxidation sites [PH] was estimated from the knowledge of the repetitive monomer unit of perfect network. These concentrations were found to be roughly the same for both matrices: $[\mathrm{PH}] \approx 14.4 \mathrm{~mol} . \mathrm{L}^{-1}$ for DGEBF-CAF and 13.7 mol. $\mathrm{L}^{-1}$ for DGEBA-CAF. All these physico-chemical characteristics have been compiled in Table 3 for the two EPO-DA matrices under study.

\subsection{Experimental procedures}

The thermal oxidation kinetics of DGEBF-CAF and DGEBA-CAF matrices was studied at 120 and $150^{\circ} \mathrm{C}$ under an oxygen partial pressure ranged between 0.21 bar (in air-ventilated ovens) and 10 bars (in autoclaves) for a minimum duration of 3 months. All the films were periodically removed from the ageing chambers and cooled to room temperature in a desiccator containing silica gel for preventing any moisture recovery prior to be characterized by FTIR spectrophotometry. The FTIR spectra were recorded in a transmission mode between 400 and $4000 \mathrm{~cm}^{-1}$ with a Perkin Elmer Frontier apparatus, after having averaged the 16 scans obtained with a minimum resolution of $4 \mathrm{~cm}^{-1}$. As already shown in a recent publication [64], the main structural modifications were observed in the carbonyl region where two new wide absorption bands appeared and grew rapidly with exposure time: one centered around $1680-1690 \mathrm{~cm}^{-1}$, and the other around $1720-1730 \mathrm{~cm}^{-1}$. As an example, Fig. 3 shows the changes over time in the FTIR spectrum of DGEBF-CAF matrix at $150^{\circ} \mathrm{C}$ under 0.21 bar of oxygen (i.e. ambient air). These two bands were assigned to amides and other types of carbonyl products, respectively. Unfortunately, the great variety of these latter products (aldehydes, carboxylic acids, phenyl formates, etc.), often resulting from oxidation induced chain scissions in the hydroxyl propyl ether segment [72], did not allow identifying them precisely. Their average concentration throughout the film thickness $[\mathrm{P}=0$ ] was determined by applying the classical Beer-Lambert's law:

$[\mathrm{P}=0]=\frac{\mathrm{OD}}{\mathrm{ep} \varepsilon}$

where OD is the optical density of the IR absorption band centered at $1720-1730 \mathrm{~cm}^{-1}$ (dimensionless), $\varepsilon$ is the corresponding molar 


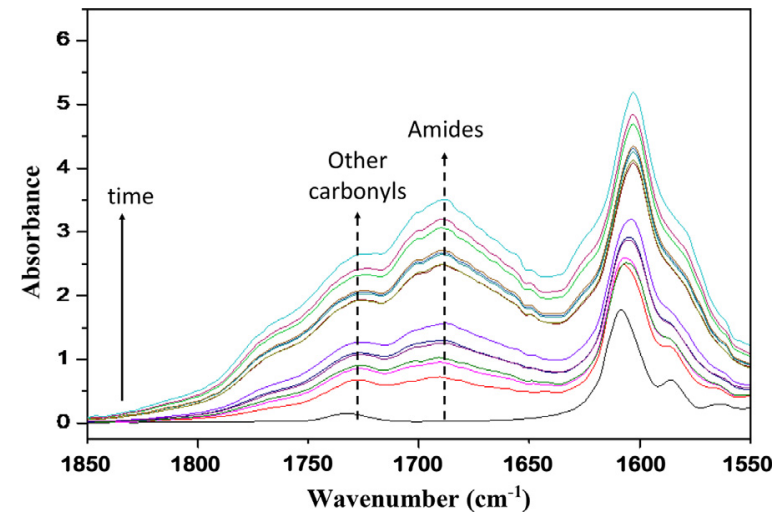

Fig. 3. Changes in the FTIR spectrum of DGEBF-CAF matrix during its thermal ageing at $150^{\circ} \mathrm{C}$ under 0.21 bar of oxygen (i.e. ambient air). The final spectrum (in sky blue) was recorded after 156 hours of thermal exposure.

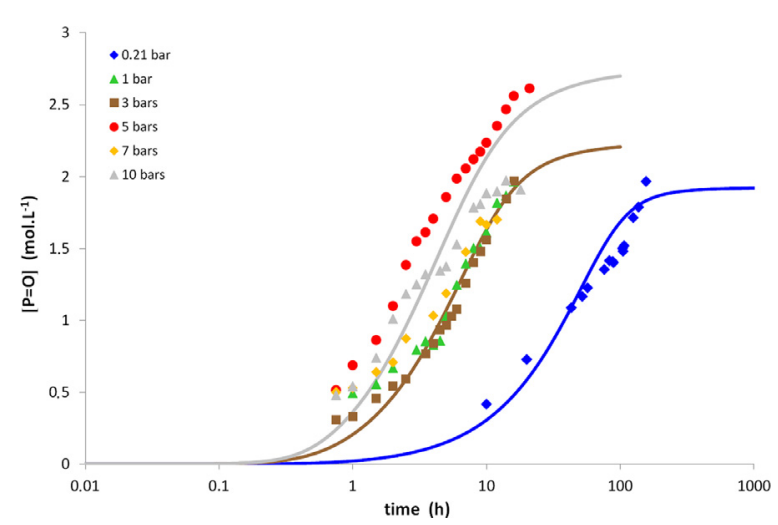

Fig. 4. Carbonyl build-up in $25 \mu \mathrm{m}$ thick films of DGEBF-CAF matrix at $150^{\circ} \mathrm{C}$ between 0.21 (ambient air) and 10 bars of oxygen. Comparison between simulations with the numerical model (solid lines) and experimental data (points) [64].

extinction coefficient (expressed in $\mathrm{L} \cdot \mathrm{mol}^{-1} \cdot \mathrm{cm}^{-1}$ ), and ep is the film thickness (in $\mathrm{cm}$ ).

For carbonyl products, typical values of $\varepsilon$ are ranged between 150 L.mol ${ }^{-1} . \mathrm{cm}^{-1}$ (for ketones) and $850 \mathrm{~L} \cdot \mathrm{mol}^{-1} . \mathrm{cm}^{-1}$ (for carboxylic acids) [65,73-76]. In a first approximation, an average value of $500 \mathrm{~L} \cdot \mathrm{mol}^{-1} \cdot \mathrm{cm}^{-1}$ was chosen for $\varepsilon$ in the present study.

\section{Checking the validity of the analytical solution}

The numerical model recently developed for predicting the thermal oxidation kinetics of the whole family of EPO-DA matrices [64] was naturally chosen to check the reliability of the analytical Equation (64) in this study. Examples of numerical simulations of experimental data between 0.21 and 10 bars of oxygen at $150^{\circ} \mathrm{C}$ for DGEBF-CAF and at $120^{\circ} \mathrm{C}$ for DGEBA-CAF are recalled in Figures 4 and 5 , respectively. It can be clearly seen that the numerical model is capable of accurately accounting for the four main successive stages commonly observed throughout the course of thermal oxidation, i.e.: the period of induction, the sharp auto-acceleration of oxidation kinetics at the end of the induction period, the steadystate regime and finally, the sudden slow-down of oxidation kinetics when the concentration of oxidation sites vanishing.

The same simulations were performed with analytical Equation (64). Examples of comparisons between the simulations with Equation (64) and the numerical model at $150^{\circ} \mathrm{C}$ for DGEBF-CAF and at $120^{\circ} \mathrm{C}$ for DGEBA-CAF are shown in Figures 6 and 7 , respectively. It can be clearly seen that Equation (64) is also capable of accurately accounting for all stages of the ther-

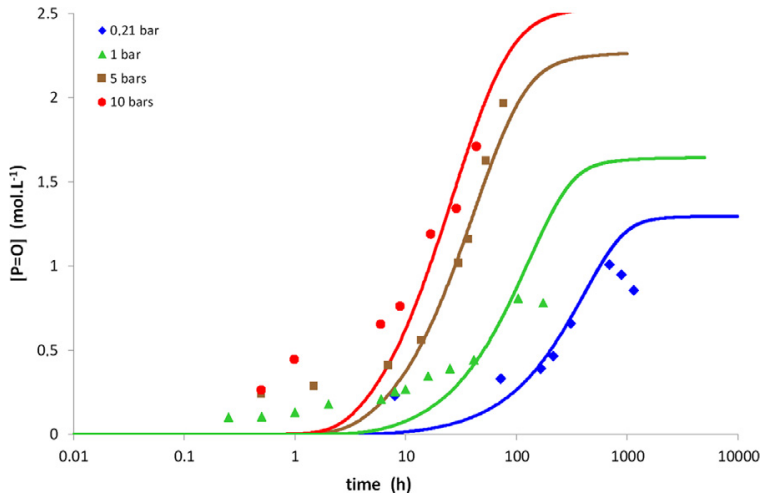

Fig. 5. Carbonyl build-up in $25 \mu \mathrm{m}$ thick films of DGEBA-CAF matrix at $120^{\circ} \mathrm{C}$ between 0.21 (ambient air) and 10 bars of oxygen. Comparison between simulations with the numerical model (solid lines) and experimental data (points) [64].

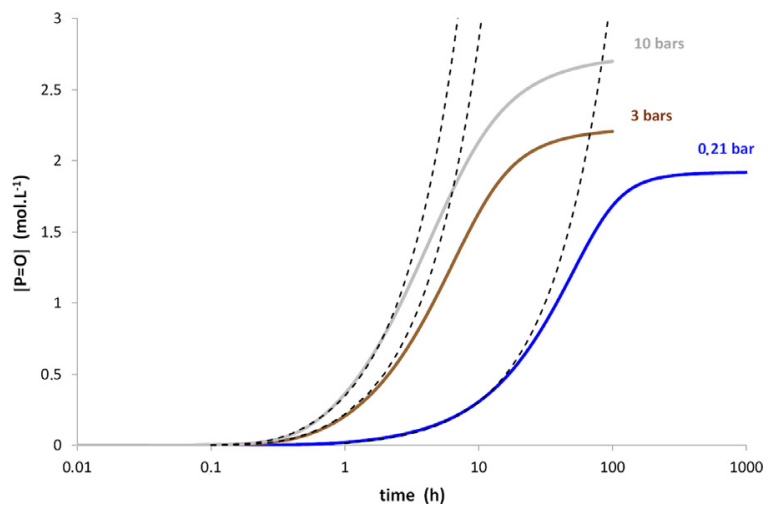

Fig. 6. Simulation of carbonyl build-up in the DGEBF-CAF matrix at $150^{\circ} \mathrm{C}$ under 0.21 (ambient air), 3 and 10 bars of oxygen. Comparison between the analytical Equation (64) (dashed black lines) and the numerical model (solid colored lines).

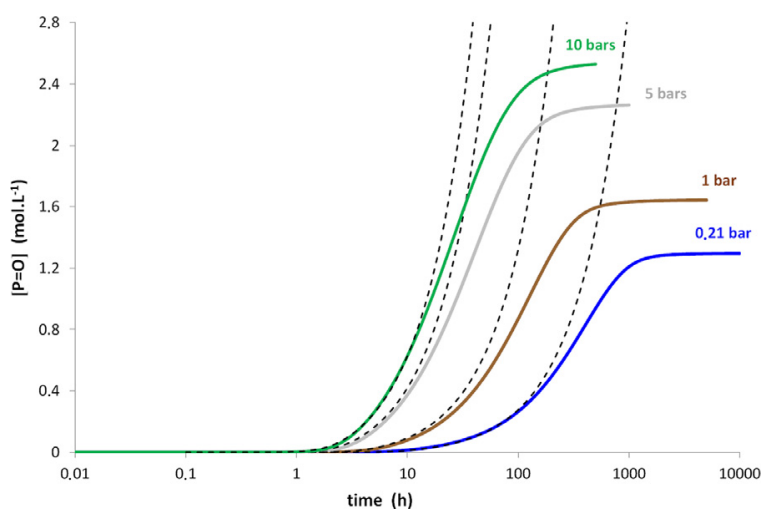

Fig. 7. Simulation of carbonyl build-up in the DGEBA-CAF matrix at $120^{\circ} \mathrm{C}$ under 0.21 (ambient air), 1, 5 and 10 bars of oxygen. Comparison between the analytical Equation (64) (dashed black lines) and the numerical model (solid colored lines).

mal oxidation kinetics, except the last one. Indeed, recall that Equation (64) was established by assuming low conversion ratios (i.e. $[\mathrm{PH}] \approx[\mathrm{PH}]_{0} \approx$ constant). For this reason, it cannot account for the sudden slow-down of oxidation kinetics at long-term. This behavioral deviation between the analytical and numerical models appears when the concentration in oxidation sites typically decreases by about ten percent, and it progressively increases with exposure time. However, since the embrittlement of EPO-DA matrices is generally observed at low conversion ratios, i.e. during the induction period or the auto-acceleration of the oxidation 
Table 4

Values of parameters used for simulating the carbonyl build-up in DGEBF-CAF and DGEBA-CAF matrices at 120 and $150^{\circ} \mathrm{C}$ with Equation (64).

\begin{tabular}{lllll}
\hline Matrix & DGEBF-CAF & DGEBA-CAF \\
\hline $\mathrm{T}\left({ }^{\circ} \mathrm{C}\right)$ & 120 & 150 & 120 & 150 \\
$\mathrm{~b}\left(\mathrm{~mol} . \mathrm{L}^{-1}\right)$ & 10 & 10 & 10 & 10 \\
$\mathrm{~S}\left(\mathrm{~mol}^{-1} \cdot \mathrm{Pa}^{-1}\right)$ & $1.45 \times 10^{-7}$ & $1.45 \times 10^{-7}$ & $1.45 \times 10^{-7}$ & $1.45 \times 10^{-7}$ \\
$\gamma_{1 \mathrm{co}}(\%)$ & 0.3 & 0.3 & 0.3 & 0.3 \\
$\gamma_{6 \mathrm{co}}(\%)$ & 0.3 & 0.3 & 0.3 & 0.3 \\
$\mathrm{r}_{0}\left(\mathrm{~mol}^{-1} \mathrm{~L}^{-1} \mathrm{~s}^{-1}\right)$ & $4.5 \times 10^{-5}$ & $2.5 \times 10^{-4}$ & $6.0 \times 10^{-5}$ & $6.5 \times 10^{-4}$ \\
$\beta\left(\mathrm{L}_{\mathrm{mol}}^{-1}\right)$ & 13 & 40 & 15 & 18 \\
$\mathrm{k}_{1 \mathrm{~b}}\left(\mathrm{~L} . \mathrm{mol}^{-1} \cdot \mathrm{s}^{-1}\right)$ & $2.0 \times 10^{-3}$ & $2.0 \times 10^{-2}$ & $2.0 \times 10^{-3}$ & $8.0 \times 10^{-3}$ \\
\hline
\end{tabular}

Table 5

Critical values of oxygen concentration and oxygen partial pressure in DGEBF-CAF and DGEBA-CAF matrices at 150 and $120^{\circ} \mathrm{C}$.

\begin{tabular}{lllll}
\hline Matrix & DGEBF-CAF & DGEBA-CAF \\
\hline $\mathrm{T}\left({ }^{\circ} \mathrm{C}\right)$ & 120 & 150 & 120 & 150 \\
$\mathrm{C}_{\mathrm{C}}\left(\mathrm{mol}_{\mathrm{L}} \mathrm{L}^{-1}\right)$ & $2.3 \times 10^{-1}$ & $7.5 \times 10^{-2}$ & $2.0 \times 10^{-1}$ & $1.7 \times 10^{-1}$ \\
$\mathrm{P}_{\mathrm{O} 2 \mathrm{C}}(\mathrm{bar})$ & 15.9 & 5.2 & 13.8 & 11.5 \\
\hline
\end{tabular}

kinetics, the domain of validity of the analytical model (and thus, Eq. 64) is largely sufficient in order to apply the current methodology for lifetime prediction thereafter. From these comparisons, it can be thus concluded that the reliability of Equation (64) is demonstrated.

The values of the seven adjustable parameters used for simulating the carbonyl build-up with Equation (64) in Figures 6 and 7 are reported in Table 4. Do not forget that four of these parameters were already fixed in previous sections from theoretical considerations (b), or determined in a previous publication [64] (S, $\gamma_{1 \text { co }}$ and $\left.\gamma_{6 \mathrm{co}}\right)$. Finally, the simulations allowed only identifying the three remaining parameters characterizing the thermal oxidation behavior of the two EPO-DA matrices: $\mathrm{r}_{0}, \beta$ and $\mathrm{K}$ (i.e. $\mathrm{k}_{1 \mathrm{~b}}$ ). Their values determined at 120 and $150^{\circ} \mathrm{C}$ call for the following comments:

i) $\mathrm{k}_{1 \mathrm{~b}}$ takes almost the same values as those recently determined with the numerical model in reference [64]. It is thus confirmed that $\mathrm{k}_{1 \mathrm{~b}}$ obeys an Arrhenius law with the same values of pre-exponential factor and activation energy given just below Equation (7).

ii) In contrast, $\beta$ and $\mathrm{r}_{0}$ show much more complicated variations with temperature because these two parameters depend on rate constants $\mathrm{k}_{3}$ and $\mathrm{k}_{6}$ (see Eq. (26) and Eq. (50)) which, as shown in reference [64], are affected by the molecular mobility and, for this reason, no longer obey an Arrhenius' law in the action zone of the glass transition. Of course, the impact of the molecular mobility on $\beta$ and $r_{0}$ is expected to be more pronounced for the DGEBF-CAF matrix because its glass transition temperature $\left(T_{g}=158^{\circ} \mathrm{C}\right.$ ) is much closer to the two exposure temperatures under investigation. This is exactly what can be seen in Table 4: When increasing the temperature from 120 to $150^{\circ} \mathrm{C}, \beta$ increases faster whereas $r_{0}$ increases slower for this epoxy matrix, in accordance with the temperature variations of $\mathrm{k}_{3}$ and $\mathrm{k}_{6}$ previously reported in reference [64].

The critical values of the oxygen concentration $C_{C}$ and oxygen partial pressure $\mathrm{P}_{\mathrm{O} 2 \mathrm{C}}$ above which oxygen excess is reached were deduced from the values of $\beta$ using Equations (26) and (27), respectively. As expected, $\mathrm{C}_{\mathrm{C}}$ and $\mathrm{P}_{\mathrm{O} 2 \mathrm{C}}$ also show complicated variations with temperature but they vary in the opposite direction of $\beta$. In the glass transition zone (i.e. at $150^{\circ} \mathrm{C}$ for DGEBF-CAF), it is found that $\mathrm{P}_{\mathrm{O} 2 \mathrm{C}}$ is about 5 bars, i.e. a value often reported for EPODA networks in the literature, e.g. in reference [77]. In the glassy domain, however, $\mathrm{P}_{\mathrm{O} 2 \mathrm{C}}$ is found to be between two and three times higher, which requires realizing thermal ageing experiments under very high oxygen partial pressures (typically 50 bars) for accessing the thermal oxidation kinetics in oxygen excess.

\section{Using the analytical solution for determining the accelerated aging conditions}

The analytical kinetic model developed in previous sections can be easily implemented into common mechanical calculation codes for determining the consequences of oxidation on mechanical properties. In addition, this model can be used to determine the accelerated aging conditions inducing a simple acceleration of the natural aging kinetics without any deformation of the structural degradation state.

To accelerate the thermal aging, it is usual to increase the exposure temperature $T$. In general, care is taken not to change of physical state (e.g. not to pass from glassy to rubbery state) because the literature reports examples of the impact of the molecular mobility on the oxidation kinetics [64]. However, as repeatedly shown in the literature, e.g. in references $[16,45]$, the rise in temperature causes a reduction in the thickness of the superficial oxidized layer (TOL), which will affect the global mechanical properties of the sample, but can also completely modify its mode of rupture when it is mechanically stressed. Fortunately, it is possible to play on another environmental factor to keep TOL constant: the oxygen partial pressure $\mathrm{P}_{\mathrm{O} 2}$.

According to Audouin et al. [23], the steady value of TOL can be estimated by using a simple scaling law:

$\mathrm{TOL} \approx\left(\frac{\mathrm{DC}}{\mathrm{r}_{\infty}}\right)^{1 / 2}$

where $C$ and $r_{\infty}$ are the oxygen concentration (Eq. 11) and the steady value of oxidation rate (Eq. 49) at the sample surface, respectively.

As already shown by Audouin et al. [23], two extreme kinetic regimes can be distinguished (see Fig. 1): i) When the oxygen concentration $C$ is much higher than its critical value $C_{C}$ above which oxygen is in excess (i.e. for $\beta C \gg 1$ ), $r_{\infty} \approx r_{0}$, thus Equation (66) writes as follows:

$\mathrm{TOL} \approx\left(\frac{\mathrm{D} \mathrm{C}}{\mathrm{r}_{0}}\right)^{1 / 2}$

The introduction of the Henry's law (11) into Equation (67) gives finally:

$\mathrm{TOL} \approx\left(\frac{\mathrm{D} \mathrm{S} \mathrm{P}_{\mathrm{O} 2}}{\mathrm{r}_{0}}\right)^{1 / 2}$

Remember that, in a given physical state (i.e. in rubbery or glassy state), $\mathrm{r}_{0}$ and $\mathrm{D}$ obey an Arrhenius law. Their respective activation energies will be noted $E_{r}$ and $E_{D}$ thereafter. In contrast, $S$ erratically varies with temperature, so that it is generally considered independent of temperature [78]. Finally, the introduction of these temperature dependences into Equation (68) leads to:

$\mathrm{TOL} \propto \mathrm{P}_{\mathrm{O} 2}^{1 / 2} \operatorname{Exp}\left(-\frac{\mathrm{E}_{\mathrm{TOL}}}{\mathrm{RT}}\right)$ 


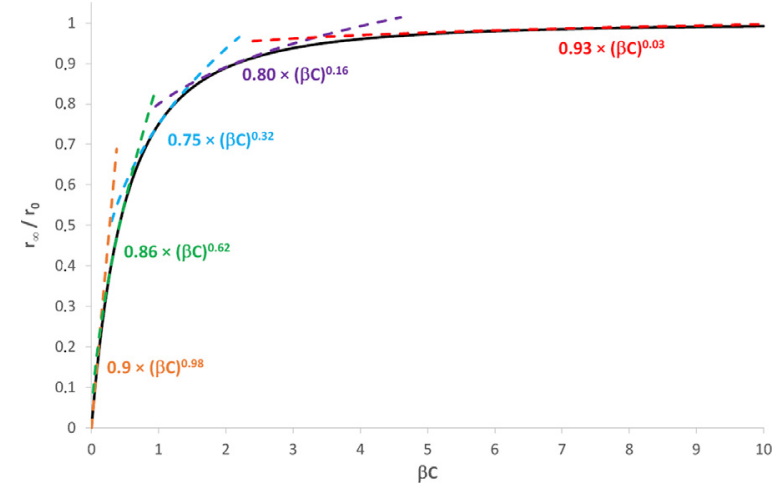

Fig. 8. Decomposition of the oxidation rate (black line) into a series of power functions (colored lines). The equations of these different functions are specified nearby their domain of validity.

with

$\mathrm{E}_{\mathrm{TOL}}=\frac{1}{2}\left(\mathrm{E}_{\mathrm{D}}-\mathrm{E}_{\mathrm{r}}\right)$

It should be pointed out that Equation (69) presents a real physical meaning as it allows accounting for the general trends of the diffusion-limited oxidation effects experimentally observed for many polymers by several authors. First, it well predicts that TOL increases according to the square root of the oxygen partial pressure $\mathrm{P}_{\mathrm{O} 2}$, as observed for instance for $\mathrm{PE}$ and its $\mathrm{EPR}$ copolymer $[23,35,38]$. In addition, as in most cases: $E_{D}<E_{r}$, i.e. $\mathrm{E}_{\mathrm{TOL}}<0$, it also predicts that TOL is a decreasing function of temperature, as already reported between 150 and $200^{\circ} \mathrm{C}$ in air for epoxy matrices $[16,45]$. In this latter case, it was also shown that Equation (69) gives the correct order of magnitude of TOL. ii) In contrast, when $\mathrm{C}$ is much lower than $\mathrm{C}_{\mathrm{C}}$ (i.e. for $\beta \mathrm{C} \ll 1$ ), $\mathrm{r}_{\infty} \approx$ $2 \mathrm{r}_{0} \beta \mathrm{C}$, thus Equation (68) writes as follows:

$\mathrm{TOL} \approx\left(\frac{\mathrm{D}}{2 \mathrm{r}_{0} \beta}\right)^{1 / 2}$

In this case, TOL only depends on temperature. Finally, the introduction of the temperature dependences in a given physical state (i.e. in rubbery or glassy state) of $\mathrm{r}_{0}, \beta$ and $\mathrm{D}$ into Equation (71) leads to:

$\mathrm{TOL} \propto \operatorname{Exp}\left(-\frac{\mathrm{E}_{\mathrm{TOL}}}{\mathrm{RT}}\right)$

with

$\mathrm{E}_{\mathrm{TOL}}=\frac{1}{2}\left(\mathrm{E}_{\mathrm{D}}-\mathrm{E}_{\mathrm{r}}-\mathrm{E}_{\beta}\right)$

Equation (72) (or a very similar formulation) was shown to be particularly suitable for capturing the general trends of the diffusion-limited oxidation in PP [37].

At intermediary oxygen concentrations, i.e. when the increase in $r_{\infty}$ is strongly slowed down with the increase in C (see Fig. 1), $r_{\infty}$ can be approached by a simple power law in each elementary interval $\Delta \mathrm{C}$ of the entire concentration range under investigation (see Fig. 8):

$\mathrm{r}_{\infty} \approx \mathrm{A}_{0}(\beta \mathrm{C})^{\mathrm{n}}$

with $\mathrm{A}=0.85 \pm 0.10$.

Exponent $\mathrm{n}$ is close to unity when $\beta \mathrm{C} \ll 1$, but decreases rapidly with $C$ to finally almost cancel when $\beta C \gg 1$.

The introduction of Equation (74) into Equation (66) leads to:

$\mathrm{TOL} \approx\left(\frac{\mathrm{D} \mathrm{C}^{1-\mathrm{n}}}{\mathrm{r}_{0} \beta^{\mathrm{n}}}\right)^{1 / 2}$
The introduction of the Henry's law (11) into Equation (75) gives finally:

$\mathrm{TOL} \approx\left(\frac{\mathrm{D} \mathrm{S}^{1-\mathrm{n}} \mathrm{P}_{\mathrm{O} 2}^{1-\mathrm{n}}}{\mathrm{r}_{0} \beta^{\mathrm{n}}}\right)^{1 / 2}$

As expected, in the general case, TOL depends both on temperature and oxygen partial pressure. Finally, the introduction of the temperature dependences in a given physical state (i.e. in rubbery or glassy state) of $\mathrm{r}_{0}, \beta, \mathrm{D}$ and $\mathrm{S}$ into Equation (76) leads to:

$\mathrm{TOL} \propto \mathrm{P}_{\mathrm{O} 2}^{(1-\mathrm{n}) / 2} \operatorname{Exp}\left(-\frac{\mathrm{E}_{\mathrm{TOL}}}{\mathrm{RT}}\right)$

with

$\mathrm{E}_{\mathrm{TOL}}=\frac{1}{2}\left(\mathrm{E}_{\mathrm{D}}-\mathrm{E}_{\mathrm{r}}-\mathrm{nE}_{\beta}\right)$

It can be noticed that Equations (77) and (78) can be considered valid over the whole range of concentrations under investigation, because they allow finding the equations of the two extreme kinetic regimes if considering the corresponding extreme values of exponent $n$, i.e. Equations (69) and (70) if taking $\mathrm{n}=0$, and Equations (72) and (73) if taking $n=1$. That is the reason why this general Equation (77) will be used, in the next paragraphs, to predict the combined effects of oxygen partial pressure and temperature.

Let us now consider a natural aging, denoted "N", characterized by a couple of mild environmental conditions $\left(\mathrm{P}_{\mathrm{O} 2 \mathrm{~N}}, \mathrm{~T}_{\mathrm{N}}\right)$. An accelerated aging " $A$ " will be representative of this natural aging only if TOL remains unchanged:

$\frac{\mathrm{TOL}_{\mathrm{N}}}{\mathrm{TOL}_{\mathrm{A}}}=1$

i.e. if the accelerated environmental conditions $\left(\mathrm{P}_{\mathrm{O} 2 \mathrm{~A}}, \mathrm{~T}_{\mathrm{A}}\right)$ satisfy the following equation:

$\left(\frac{\mathrm{P}_{\mathrm{O} 2_{\mathrm{N}}}}{\mathrm{P}_{\mathrm{O} 2_{\mathrm{A}}}}\right)^{\frac{1-\mathrm{n}}{2}} \operatorname{Exp}\left[-\frac{\mathrm{E}_{\mathrm{TOL}}}{\mathrm{R}}\left(\frac{1}{\mathrm{~T}_{\mathrm{N}}}-\frac{1}{\mathrm{~T}_{\mathrm{A}}}\right)\right]=1$

i.e.

$\mathrm{P}_{\mathrm{O} 2_{\mathrm{A}}}=\mathrm{P}_{\mathrm{O} 2_{\mathrm{N}}} \operatorname{Exp}\left[-\frac{2 \mathrm{E}_{\mathrm{TOL}}}{(1-\mathrm{n}) \mathrm{R}}\left(\frac{1}{\mathrm{~T}_{\mathrm{N}}}-\frac{1}{\mathrm{~T}_{\mathrm{A}}}\right)\right]$

Equation (81) predicts that the conditions for accelerating natural ageing can be represented by a curve of exponential shape in the $\left(\mathrm{P}_{\mathrm{O} 2}, \mathrm{~T}\right)$ map.

Let us now consider the cruising flight conditions of a commercial airliner: $\mathrm{P}_{\mathrm{O} 2_{\mathrm{N}}}=0.21$ bar (i.e. for ambient air) and $\mathrm{T}_{\mathrm{N}}=70^{\circ} \mathrm{C}$. In these conditions, TOL is typically $1.2 \mathrm{~mm}$ for EPO-DA matrices [45]. Let us only focus on accelerated ageing conditions allowing to significantly reduce the duration of the ageing experiments, in particular high values of $\mathrm{P}_{\mathrm{O} 2}$ for which it can be assumed that $\mathrm{n} \ll 1$ (see Fig. 8). In this case, Equation (81) can be simplified as follows:

$\mathrm{P}_{\mathrm{O}_{\mathrm{A}}}=\mathrm{P}_{\mathrm{O} 2_{\mathrm{N}}} \operatorname{Exp}\left[-\frac{2 \mathrm{E}_{\mathrm{TOL}}}{\mathrm{R}}\left(\frac{1}{\mathrm{~T}_{\mathrm{N}}}-\frac{1}{\mathrm{~T}_{\mathrm{A}}}\right)\right]$

An example of accelerated ageing conditions predicted with Equation (82) has been plotted in Fig. 9 for the DGEBA-CAF matrix in glassy state $\left(\mathrm{T}_{\mathrm{g}} \approx 182^{\circ} \mathrm{C}\right)$. The value of $\mathrm{E}_{\mathrm{D}}$ recently identified between 10 and $110^{\circ} \mathrm{C}$ for the EPO-DA matrices cross-linked with an aromatic diamine hardener [64] was used for this calculation. In addition, $E_{r}$ was estimated from the activation energies of the rate constants $\mathrm{k}_{3}$ and $\mathrm{k}_{6}$ in glassy state determined for the whole family of EPO-DA matrices in the same publication [64]. Indeed, from Equation (50), it can shown that:

$\mathrm{E}_{\mathrm{r}}=2 \mathrm{E}_{3}-\mathrm{E}_{6}$

Finally, $\mathrm{E}_{\mathrm{TOL}}$ was deduced from Equation (70). The corresponding values of $E_{\mathrm{D}}, \mathrm{E}_{\mathrm{r}}$ and $\mathrm{E}_{\mathrm{TOL}}$ are compiled in Table 6 . 


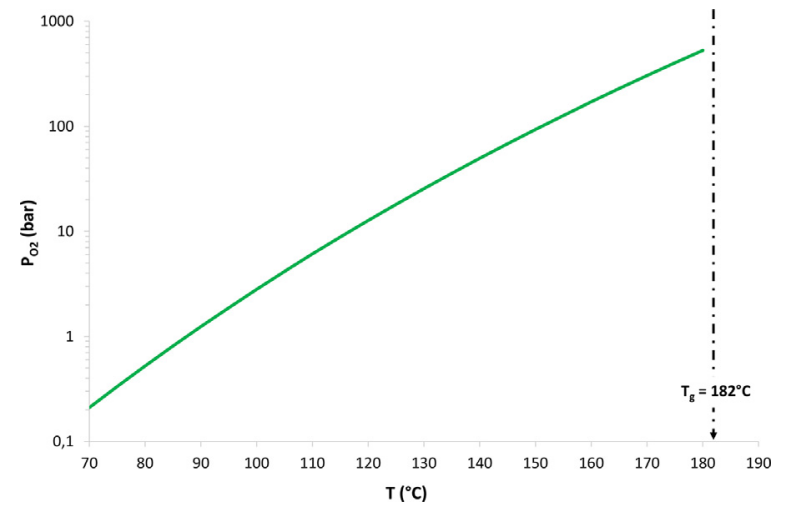

Fig. 9. Accelerated aging conditions representative of a natural aging of DGEBA-CAF matrix under 0.21 bar of oxygen at $70^{\circ} \mathrm{C}$ predicted with Equation (82).

\section{Table 6}

Activation energies of oxygen diffusion, oxidation rate and thickness of oxidized layer for DGEBF-CAF and DGEBA-CAF matrices in glassy state.

\begin{tabular}{ll}
\hline $\mathrm{E}_{\mathrm{D}}\left(\mathrm{kJ} \cdot \mathrm{mol}^{-1}\right)$ & 20 \\
$\mathrm{E}_{\mathrm{r}}\left(\mathrm{kJ} \cdot \mathrm{mol}^{-1}\right)$ & 112 \\
$\mathrm{E}_{\mathrm{TOL}}\left(\mathrm{kJ} \cdot \mathrm{mol}^{-1}\right)$ & -46 \\
\hline
\end{tabular}

In Fig. 9, it can be observed that the oxygen partial pressure should be considerably increased, typically up to 527 bars for DGEBA-CAF, in order to keep TOL at a constant value when the temperature is raised up to $180^{\circ} \mathrm{C}$. This result is not surprising because when $\beta C \gg 1$, the oxidation rate $\mathrm{r}_{\infty}$ is almost no longer dependent on $\mathrm{P}_{\mathrm{O} 2}$. It is therefore increasingly difficult to counterbalance the effects of an increase in temperature by an increase in oxygen partial pressure. In other words, to have an effect of $\mathrm{P}_{\mathrm{O} 2}$ comparable to that of temperature on TOL, $\mathrm{P}_{\mathrm{O} 2}$ must be increased much more than temperature.

Such extreme environmental conditions are necessary to avoid a deformation of the structural degradation state and thus, to guarantee the reliability of the results of mechanical tests. Unfortunately, they may be very difficult to access with the current experimental tools available in research laboratories.

\section{Conclusion}

The system of differential equations derived from the so-called closed-loop mechanistic scheme was solved analytically without making the usual simplifying assumptions that seriously degraded the reliability of all the analytical kinetic models established until then, but only generalizing the proportionalities observed between the different steady concentrations of reactive species: [POOH], $\left[\mathrm{PO}_{2}{ }^{\bullet}\right]$ and $\left[\mathrm{P}^{\bullet}\right]$, to the entire course of thermal oxidation. These proportionality assumptions were found quite realistic. They led to a sounder analytical kinetic model capable of accurately describing the three first stages of the thermal oxidation kinetics: the induction period, the auto-acceleration of the oxidation kinetics at the end of the induction period, and the steady-state regime. This new kinetic model was used to identify the thermal oxidation behavior at 120 and $150^{\circ} \mathrm{C}$ in a large range of oxygen partial pressures (between 0.21 and 10 bars) of two epoxy-diamine matrices considered for composite structure applications at low to moderate temperatures in the civil aeronautical sector. It can be now easily implemented into commercial mechanical calculation codes for determining the consequences of oxidation on mechanical properties.

In addition, the new analytical model was used to predict the accelerated aging conditions inducing a simple acceleration of the natural aging kinetics without any deformation of the structural degradation state. These accelerated aging conditions correspond to a curve of exponential shape in the $\left(\mathrm{P}_{\mathrm{O} 2}, \mathrm{~T}\right)$ map. It was found that the oxygen partial pressure must be increased much more than the temperature to avoid any deformation of the structural degradation state in the two EPO-DA matrices under study. However, accessing such extreme environmental conditions could pose almost insurmountable problems in practice.

\section{Declaration of Competing Interest}

The authors declare that they have no known competing financial interests or personal relationships that could have appeared to influence the work reported in this paper.

The authors declare the following financial interests/personal relationships which may be considered as potential competing interests.

\section{CRediT authorship contribution statement}

Xavier COLIN: Conceptualization, Methodology, Software, Validation, Writing - original draft. Fatima ESSATBI: Investigation. Justine DELOZANNE: Writing - review \& editing. Gurvan MOREAU: Resources, Writing - review \& editing, Supervision, Project administration, Funding acquisition.

\section{References}

[1] W.B. Alston, in: Characterization of PMR-15 in thermooxidatively exposed graphite fiber composites, In: Proceedings of the 12th National SAMPE Technical Conference, Seattle, Washington, October 7-9, 1980.

[2] J.R. Kerr, J.F. Haskins, Effects of 50,000 h of thermal aging on graphite/epoxy and graphite/polyimide composites, AIAA J 22 (1) (1984) 96-102.

[3] P.R. Young, A.C. Chang, FTIR characterization of thermally cycled PMR-15 composites, in: Proceedings of the 33 SAMPE Symposium and Exhibition, 1988, pp. 538-550. March 7-10.

[4] K.N. Street, A.J. Russel, F. Bonsang, Thermal damage effects on delamination toughness of a graphite/epoxy composite, Compos. Sci. Technol. 32 (1988) $1-14$.

[5] D.A. Scola, J.H. Vontell, Mechanical properties and mechanism of the degradation process of $316^{\circ} \mathrm{C}$ isothermally aged graphite fiber/PMR-15 composites, Polym. Eng. Sci. 31 (1) (1991) 6-13.

[6] J.D. Nam, J.C. Seferis, Anisotropic thermo-oxidative stability of carbon fiber reinforced polymeric composites, SAMPE Quart 24 (1) (1992) 10-18.

[7] I.M. Salin, J.C. Seferis, Anisotropic effects in thermogravimetry of polymeric composites, J. Polym. Sci. 31 (8) (1993) 1019-1027.

[8] K.J. Bowles, D. Jayne, T.A. Leonhardt, D. Bors, Thermal stability relationships between PMR-15 resin and its composites, J. Adv. Mater. 26 (1) (1994) 23-32.

[9] A. Skontorp, M.S. Wong, S.S. Wang, High temperature anisotropic oxidation of carbon fiber reinforced polyimide composites: Theory ad experiments, in: Proceedings of the $10^{\text {th }}$ International Conference on Composite Materials, Whistler B.C., Canada, August 14-18, 1995, pp. 375-384.

[10] H. Parvatareddy, J.Z Wang, J.J. Lesko, D.A. Dillard, K.L. Reifsnider, Evaluation of chemical aging/oxidation in high performance composites via the Vickers micro-indentation technique, J. Compos. Mater. 30 (2) (1996) 210-230.

[11] T.K. Tsotsis, Long-term thermo-oxidative aging in composite materials: Experimental methods, Compos. Sci. Technol. 32 (11) (1998) 1115-1135.

[12] T.K. Tsotsis, S.M. Lee, Long-term thermo-oxidative aging in composite materials: Failure mechanisms, Compos. Sci. Technol. 58 (3-4) (1998) 355-368.

[13] X. Colin, C. Marais, J.P. Favre, Damage/weight loss relationship of polymer matrix composites under thermal ageing, in: Proceedings of the 12 International Conference on Composites Materials, Paris, France, July 5-7, 1999 article no. 311.

[14] T.K. Tsotsis, S. Keller, K. Lee, J. Bardis, J. Bish, Aging of polymeric composite specimens for 5000 hours at elevated pressure and temperature, Compos. Sci. Technol. 61 (2001) 75-86.

[15] M.C. Lafarie-Frenot, S. Rouquie, Influence of the oxidative environments on damage in C/epoxy laminates subjected to thermal cycling, Compos. Sci. Technol. 64 (10-11) (2004) 1725-1735.

[16] X. Colin, A. Mavel, C. Marais, J. Verdu, Interaction between cracking and oxidation in organic matrix composites, J. Compos. Mater. 39 (15) (2005) 1371-1389.

[17] G.A. Schoeppner, G.P. Tandon, E.R. Ripberger, Anisotropic oxidation and weight loss in PMR-15 composites, Compos. Part A: Appl. Sci. Manuf. 38 (2007) 890-904.

[18] G.P. Tandon, W.R. Ragland, G.A. Schoeppner, Using optical microscopy to monitor anisotropic oxidation growth in high-temperature polymer matrix composites, J. Compos. Mater. 43 (5) (2009) 583-603. 
[19] G.P. Tandon, K.V. Pochiraju, Heterogeneous thermo-oxidative behavior of multidirectional laminated composites, J. Compos. Mater. 45 (4) (2011) 415-435.

[20] G.P. Tandon, in: Characterization of thermo-oxidation in laminated and textile composites, In: Long-term durability of polymer matrix composites, K.V. Pochiraju, G.P. Tandon and G.A. Schoeppner eds, Springer, New York, 2012, pp. 345-382. Chap. 9.

[21] X. Colin, J. Verdu, in: Aging of organic matrix composite materials, In: Wiley encyclopedia of composites, 2nd edition, vol. 1/5, L. Nicolais, A. Borzacchielo and S.M. Lee eds, John Wiley \& Sons Ltd, New York, 2012, pp. 35-49. Chap. 4.

[22] K.T. Gillen, R.L. Clough, in: Techniques for monitoring heterogeneous oxidation of polymers, In: Handbook of polymer science and technology, Vol. 2, M.P. Cheremisinoff ed, Marcel Dekker Inc., New York, 1989, pp. 167-202.

[23] L. Audouin, V. Langlois, J. Verdu, J.C.M. De Bruijn, Review: Role of oxygen diffusion in polymer ageing: Kinetic and mechanical aspects, J. Mater. Sci. 29 (1994) 569-583.

[24] X. Colin, J. Verdu, in: Mechanisms and kinetics of organic matrix thermal oxidation, In: Long-term durability of polymer matrix composites, K.V. Pochiraju, G.P. Tandon and G.A. Schoeppner eds, Springer, New York, 2012, pp. 311-343. Chap. 8.

[25] K.J. Bowles, D. Jayne, T.A. Leonhardt, Isothermal aging effect on PMR15, SAMPE Ouart 24 (2) (1993) 2-9.

[26] M.A.B. Meador, C.E. Lowell, P.J. Cavano, P. Herrera-Fierro, On the oxidative degradation of nadic endcapped polyimides: I- Effect of thermocycling on weight loss and crack formation, High Perform. Polym. 8 (1996) 363-379.

[27] J.B. Nelson, in: Thermal ageing of graphite/polyimide composites, In: ASTM STP-813: Long-term behavior of composites, T.K. O’Brien ed, American Society for Testing and Materials, Philadelphia, 1983, pp. 206-221.

[28] K.J. Bowles, A. Meyers, in: Specimen geometry effects on graphite/PMR-15 composites during thermos-oxidative aging, Proceedings of the 31st International SAMPE Symposium and Exhibition, Los Angeles, April 7-10, 1986, pp. 1285-1299.

[29] K.J. Bowles, G. Nowak, Thermo-oxidative stability studies of Celion 6000/PMR-15 unidirectional composites, PMR-15 and Celion 6000 fiber, J. Compos. Mater. 22 (6) (1988) 966.

[30] I. Salin, J.C. Seferis, Anisotropic degradation of polymeric composites: From neat resin to composite, Polym. Compos. 17 (3) (1996) 430-442.

[31] I. Salin, J.C. Seferis, Mass transfer effects in degradation of bismaleimide matrix composite, J. Appl. Polym. Sci. 62 (7) (1996) 1023-1027.

[32] A.V. Tobolsky, D.J. Metz, R.B. Mesrobian, Low temperature oxidation of hydrocarbons. The phenomenon of maximum rates, J. Amer. Chem. Soc. 72 (1950) 1942-1952.

[33] C.R. Boss, J.C.W. Chien, Oxygen diffusion limitation in autoxidation of polypropylene, J. Polym. Sci.: Part A: Polym. Chem. 4 (6) (1966) 1543-1551.

[34] G.C. Furneaux, K.J. Ledbury, A. Davis, Photo-oxidation of thick polymer samples. Part I: The variation of photo-oxidation with depth in naturally and artificially weathered low density polyethylene, Polym. Degrad. Stab. 3 (6) (1981) 431-442.

[35] T. Seguchi, S. Hashimoto, K. Arakawa, N. Hayakawa, W. Kawakami, I. Kuriyama, Radiation induced oxidative degradation of polymers. Part I: Oxidation region in polymeric films irradiated in oxygen under pressure, Radiat. Phys. Chem. 17 (4) (1981) 195-201.

[36] A.V. Cunliffe, A. Davis, Photo-oxidation of thick polymer samples, Polym. Degrad. Stab. 4 (1) (1982) 17-37.

[37] S.G. Kiryushkin, Y.A. Shlyapnikov, Diffusion-controlled polymer oxidation, Polym. Degrad. Stab. 23 (1989) 185-192.

[38] K.M.B. Jansen, Analytical approximation of degradation profiles in polymer products, Polym. Eng. Sci. 34 (21) (1994) 1619-1627.

[39] R.A. Cunningham, H.L. McManus, in: Coupled diffusion-reaction model for predicting the distribution of degradation in polymer matrix composites, In: Proceedings of the ASME International Mechanical Engineering Congress and Exposition, Vol. 52, American Society of Mechanical Engineers, Atlanta, 1996, pp. 353-359.

[40] H.L. McManus, R.A. Cunningham, in: Materials and mechanics analyses of durability tests for high-temperature polymer matrix composites, In: ASTM STP 1302: High temperature and environmental effects on polymeric composites, Vol. 2, T.S. Gates and A.H. Zureick eds, American Society for Testing Materials, West Conshohocken PA, 1997, pp. 1-17.

[41] L.K. Crews, H.L. McManus, in: Modelling the high temperature degradation of graphite/epoxy, In: Proceedings of the $12^{\text {th }}$ Technical Conference on Composite Materials, American Society for Composites, Detroit, MI, October 1997, pp. $1123-1132$.

[42] H.L. McManus, B.J. Foch, R.A. Cunningham, Mechanism-based modeling of long-term degradation, J. Compos. Technol. Res. 22 (3) (2000) 146-152.

[43] L. Audouin, V. Gueguen, A. Tcharkhtchi, J. Verdu, Close-loop mechanistic schemes for hydrocarbon polymer oxidation, J. Polym. Sci.: Part A: Polym. Chem. 33 (6) (1995) 921-927.

[44] X. Colin, L. Audouin, J. Verdu, Determination of thermal oxidation rate constants by an inverse method. Application to polyethylene, Polym. Degrad. Stab. 86 (2004) 309-321.

[45] X. Colin, C. Marais, J. Verdu, A new method for predicting the thermal oxidation of thermosets. Application to an amine crosslinked epoxy, Polym. Test. 20 (7) (2001) 795-803.

[46] X. Colin, C. Marais, J. Verdu, Thermal oxidation kinetics for a poly-(bismaleimide), J. Appl. Polym. Sci. 82 (14) (2001) 3418-3430.

[47] L. Olivier, N.Q. Ho, J.C. Grandidier, M.C. Lafarie-Frenot, Characterization by ul- tra-micro-indentation of an oxidized epoxy polymer. Correlation with the predictions of a kinetic model of oxidation, Polym. Degrad. Stab. 93 (2) (2008) 489-493.

[48] G.P. Tandon, K.V. Pochiraju, G.A. Schoeppner, Modeling of oxidative development in PMR-15 resin, Polym. Degrad. Stab. 91 (2006) 1861-1869.

[49] K.V. Pochiraju, G.P. Tandon, Modeling thermo-oxidative layer growth in high-temperature resins, J. Eng. Mater. Technol. 128 (2006) 107-116.

[50] L. Olivier, C. Baudet, D. Bertheau, J.C. Grandidier, M.C. Lafarie-Frenot, Development of experimental, theoretical and numerical tools for studying thermo-oxidation of CFRP composites, Compos.: Part A: Appl. Sci. Manuf. 40 (8) (2009) 1008-1016.

[51] E. Barjasteh, E.J. Bosze, Y.I. Tsai, S.R. Nutt, Thermal ageing of fiberglass/carbon-fiber hybrid composites, Compos.: Part A: Appl. Sci. Manuf. 40 (12) (2009) 2038-2045.

[52] E. Barjasteh, N. Kar, S.R. Nutt, Effect of filler on thermal aging of composites for next-generation power lines, Compos.: Part A: Appl. Sci. Manuf. 42 (12) (2011) 1873-1882.

[53] K.V. Pochiraju, G.P. Tandon, G.A. Schoeppner, Evolution of stress and deformations in high temperature polymer matrix composites during thermo-oxidative aging, Mech. Time-Deped. Mater. 12 (1) (2008) 45-68.

[54] K.V. Pochiraju, G.P. Tandon, Interaction of oxidation and damage in high temperature polymeric matrix composites, Compos. Part A: Appl. Sci. Manuf. 40 (12) (2009) 1931-1940.

[55] G.P. Tandon, K.V. Pochiraju, Heterogeneous thermo-oxidative behavior of multidirectional laminated composites, J. Compos. Mater. 45 (4) (2011) 415-435.

[56] K.V. Pochiraju, Modeling thermo-oxidative aging and degradation of composites, in: K.V. Pochiraju, G.P. Tandon, G.A. Schoeppner (Eds.), Long-term durability of polymer matrix composites, Springer, New York, 2012, pp. 383-425. Chap. 10.

[57] E. Hairer, G. Wanner, Solving ordinary differential equations II. Stiff and differential-algebraic problems, Springer, Berlin, 1991.

[58] X. Colin, J. Verdu, Strategy for studying thermal oxidation of organic matrix composites, Compos. Sci. Technol. 65 (2005) 411-419.

[59] M.C. Lafarie-Frenot, J.C. Grandidier, M. Gigliotti, L. Olivier, X. Colin, J. Verdu, J. Cinquin, Thermo-oxidation behaviour of composite materials at high temperatures: A review of research activities carried out within the COMEDI program, Polym. Degrad. Stab. 95 (6) (2010) 965-974.

[60] J. Cinquin, X. Colin, B. Fayolle, M. Mille, S. Terekhina, L. Chocinski-Arnault, M. Gigliotti, J.-C. Grandidier, M.-C. Lafarie-Frenot, M. Minervino, C. Cluzel, F. Daghia, P. Ladeveze, F. Zhang, Thermo-oxidation behavior of organic matrix composite materials at high temperatures, Adv. Aircr. Spacecr. Sci. 3 (2) (2016) 171-195.

[61] S. Konica, T. Sain, A thermodynamically consistent chemo-mechanically coupled large deformation model for polymer oxidation, J. Mech. Phys. Solids 137 (2020) Article no. 103858.

[62] S. Plantet, X. Colin, P. Chinesta, G. Coffignal, Résolution d'un problème raide de cinétique chimique, in: Proceedings of the 18ème Congrès Français de Mécanique (CFM'07), Association Française de Mécanique, Grenoble, France, August 27-31, 2007 Article no. 0376

[63] X. Colin, G. Teyssèdre, M. Fois, in: Ageing and degradation of multiphase polymer systems, dans Handbook of Multiphase Polymer Systems, Vol. 2/2, A Boudenne, L. Ibos, Y. Candau and S. Thomas eds, John Wiley \& Sons Ltd, Chichester, 2011, pp. 797-841. Chap. 21.

[64] X. Colin, F. Essatbi, J. Delozanne, G. Moreau, Towards a general kinetic model for the thermal oxidation of epoxy-diamine networks. Effect of the molecular mobility around the glass transition temperature, Polym. Degrad. Stab. 181 (2020) Article no. 109314.

[65] M.Da Cruz, L. Van Schoors, K. Benzari, X. Colin, Thermo-oxidative degradation of additive free polyethylene. Part I- Analysis of the chemical modifications at molecular and macromolecular scales, J. Appl. Polym. Sci. 133 (18) (2016) Article no. 43287.

[66] J. Huang, W. Minne, R. Drozdzak, G. Recher, P.Y. Le Gac, E. Richaud, Thermal oxidation of poly(dicyclopentadiene). Decomposition of hydroperoxides, Polym. Degrad. Stab. 174 (2020) Article no. 109102.

[67] L. Audouin, L. Achimsky, J. Verdu, in: Modelling of hydrocarbon polymer oxidation, In: Handbook of polymer degradation, 2nd edition, S. Halim Hamid ed. Marcel Dekker, New York, 2000, pp. 727-763. Chap. 20.

[68] X. Colin, B. Fayolle, L. Audouin, J. Verdu, The classical kinetic model for radical chain oxidation of hydrocarbon substrates initiated by bimolecular hydroperoxide decomposition, Int. J. Chem. Kin. 38 (11) (2006) 666-676.

[69] K.T. Gillen, J. Wise, R.L. Clough, General solution for the basic autoxidation scheme, Polym. Degrad. Stab. 47 (1995) 149-161.

[70] A. François-Heude, E. Richaud, A. Guinault, E. Desnoux, X. Colin, Impact of oxygen transport properties on polypropylene thermal oxidation. Part 1: Effect of oxygen solubility, J. Appl. Polym. Sci. 132 (5) (2015) Article no. 41441.

[71] S. Terekhina, M. Mille, B. Fayolle, X. Colin, Oxidation induced changes in viscoelastic properties of a thermostable epoxy matrix, Polym. Sci. Ser. A 55 (10) (2013) 614-624.

[72] V. Bellenger, J. Verdu, Oxidative skeleton breaking in epoxy-amine networks, J. Appl. Polym. Sci. 30 (1) (1985) 363-375.

[73] M.St.C. Flett, Intensities of some group characteristic infra-red bands, Spectrochim. Acta 18 (1962) 1537-1556.

[74] W.-D. Domke, H. Steinke, Oxidative structures in polyolefins: FT-IR method of quantitative determination, J. Polym. Sci.: Part A: Polym. Chem. 24 (10) (1986) 2701-2705. 
[75] J. Lacoste, D.J. Carlsson, Gamma-, photo-, and thermally-initiated oxidation of linear low density polyethylene: A quantitative comparison of oxidation products, J. Polym. Sci.: Part A: Polym. Chem. 30 (1992) 493-500.

[76] A. Barth, Infrared spectroscopy of proteins, Biochim. Biophys. Acta 1767 (2007) 1073-1101.
[77] L. Olivier, Prévision du vieillissement thermos-oxydant de composites à matrice organique dédiés à l'aéronautique: Prise en compte des couplages multiphysiques, PhD thesis, Université de Poitiers, France, 2008.

[78] D.W. Van Krevelen, K.Te Nijenhuis, Properties of Polymers: Their correlation with chemical structure; their numerical estimation and prediction from additive group contributions, 4th Edition, Elsevier, Amsterdam, 2009. 